\title{
Abstracts of the Academic Medical Congress of Piaui (COMAPI) 2019
}

01.

\author{
ANALYSIS OF CASES OF HOSPITALIZATIONS FOR TREATMENT OF \\ DIABETES MELLITUS AND COMBINED DIABETIC FOOT IN THE STATE \\ OF PIAUI \\ Társilla Carvalho Borges', Teresa Raquel Holanda Cipriano \\ Saraiva', Helena Moura Carvalho', Sarah Maria Monteiro Soares \\ Costa De Holanda', Lucas Jesuino Lobão Alencar Raulino Barbosa', \\ Cíntia Maria De Melo Mendes' \\ 'Uninovafapi University Center
}

INTRODUCTION: Diabetes Mellitus (DM) is a chronic disease associated with microvascular and macrovascular disorders that result in increased utilization of health services and high hospitalization rates. Diabetic foot consists of "soft tissue infection, ulceration and / or destruction associated with neurological changes and varying degrees of peripheral artery disease (PAD) in the lower limbs" (International Diabetic Foot Working Group, 2001) and remains the complication most common and the most common cause of prolonged hospitalizations and non-traumatic lower limb amputations. OBJECTIVES: Carry out quantitative and comparative analysis of cases of hospitalizations for treatment of DM and treatment of complicated diabetic foot in the state of Piauí, as well as the average days of hospital stay. METHODS: Descriptive-analytical-ecological study using data on hospitalizations for treatment of DM and complicated diabetic foot, hospitalizations for lower limb amputation and the average length of stay. Data were collected in the DATASUS-TabNet System, from May 2014 to April 2019 in the state of Piauí. RESULTS: During the analyzed period, 17,738 hospitalizations were performed for DM treatment. Of these, $4.51 \%$ were for treatment of complicated diabetic foot, which mostly resulted in lower limb amputation. The average hospital stay was 4.3 days for DM treatment, while for complicated diabetic foot treatment it was 6.7 days, representing a $55.9 \%$ increase in bed stay and occupation. CONCLUSION: Comprehensive followup of diabetic patients should be performed in Primary Care ( $\mathrm{PH})$ through an educational approach, encouraging daily and adequate care of the lower limbs, as well as the identification and intervention of predictive factors for ulcer formation and amputation. Through these actions, there will be effective prevention and early intervention, reducing hospitalizations, morbidity and mortality in diabetic patients.

02.

\section{EPIDEMIOLOGICAL ANALYSIS OF UROLYTIASIS HOSPITALIZATION IN PIAUÍ}

Társilla Carvalho Borges', Teresa Raquel Holanda Cipriano Saraiva ${ }^{1}$, Helena Moura Carvalho', Bárbara Louise Freire Barbosa², Cíntia Maria De Melo Mendes ${ }^{1}$

'Uninovafapi University Center. ${ }^{2}$ Federal University of Piaui

INTRODUCTION: Urolithiasis is a pathology with high prevalence and recurrence, related to supersaturation / urinary crystallization, reduction of water intake / urinary output and crystallization inhibitors (citrate, pyrophosphate, magnesium, etc.). The epidemiological and lithogenic factors of urolithiasis involve: race, gender, age, nutritional and dietary aspects and physical activity. OBJECTIVES: To analyze the epidemiological trends and profile associated with hospitalizations for urolithiasis in the state of Piauí. METHODS: This is a cross-sectional study with data on hospital morbidity by place of hospitalization due to urolithiasis in the state of Piauí, from April 2014 to April 2019, obtained from the DATASUS-TabNet System.
Data were analyzed to identify the overall male and female prevalence of hospitalizations for urolithiasis, the distribution by age, mean length of stay and average value of hospitalizations. RESULTS: During the study period, complaints for urolithiasis accounted for 5,190 of hospital admissions, of which 22.9\% occurred between April 2015 and March 2016. The average length of stay in the hospital was 3.7 days and the average cost. of these hospitalizations was R \$ 421.66. During the five years analyzed, $52.7 \%$ of hospitalizations were female patients, while $47.3 \%$ were male patients. In addition, $23 \%$ of hospitalizations were in the $30-39$ age group, most clearly affecting the brown-colored population (52.6\%). CONCLUSION: Hospitalizations for urolithiasis had a high impact on public health and, in the period observed, were more common in women than in men, contrary to what is evidenced in the literature. Preventive treatment is of fundamental importance through measures such as increased water intake, decreased animal protein in the diet, physical activity, use of potassium citrate - depending on the composition of the calculation. This information is extremely useful and can help in structuring and optimizing health programs aimed at the prevention and treatment of urolithiasis in Brazil.

03. EPIDEMIOLOGICAL ANALYSIS OF LEPROSY BETWEEN 2015 AND 2017 IN THE METROPOLISES OF TERESINA (PI) AND SÃO PAULO (SP) Helena Moura de Carvalho'; Teresa Raquel Holanda Cipriano Saraiva'; Társilla Carvalho Borges'; Sarah Maria Monteiro Soares Costa de Holanda'; Lucas Jesuíno Lobão Alencar Raulino Barbosa'; Magda Coeli Vitorino Sales Coelho'.

1 University Center Uninovafapi

INTRODUCTION: Leprosy is a chronic disease, transmissible, of compulsory notification and mandatory investigation throughout the national territory. It has as etiological agent the Micobacterium leprae, bacillus that has the ability to infect large number of individuals. Your infection can affect people of both sexes and of any age. However, a long period of exposure to the bacterium is needed, and only a small portion of the infected population really gets sick. This pathology is strongly related to unfavorable economic, social and environmental conditions. OBJECTIVE: To describe the epidemiological aspects of reported cases of leprosy in Teresina (PI) and São Paulo (SP). METHODS: A cross-sectional study of leprosy was conducted in Teresina and São Paulo. The data source, available on the DATASUS-eSUS platform, is from the information system of notifiable diseases and the general coordination in leprosy and disease in elimination. The following variables were considered for analysis: year, age and class in the diagnosis. Through these data, percentages and comparisons were obtained. RESULTS: 1220 cases of leprosy were reported in the greater Teresina, with the highest number of cases in $2017(36.31 \%)$. In São Paulo, 788 cases were reported, with the highest number of cases in 2015 $(39.72 \%)$. In Teresina, the greatest impairment was male (53.93\%), information that has a correlation with greater exposure to risk factors. In São Paulo, males predominated through 412 cases. Regarding the class in the diagnosis, Teresina presented a multibacillary majority $(62.62 \%)$, having 2017 the most expressive year $(40.05 \%)$. São Paulo also obtained a multibacillary majority (69.16\%), being 2016 the most expressive year (37.61\%). CONCLUSION: Leprosy is still an endemic disease, prevalent among males, in the analyzed sites. However, Teresina has a more expressive number of cases in relation to São Paulo. Thus, it is important that there is the realization of policies for the surveillance and control of this problem. 
04

\section{PARNAÍBA (PI) AND LARGER FIELD (PI)}

Helena Moura Carvalho', Bárbara Louise Freire Barbosa², Társilla Carvalho Borges ${ }^{1}$, Teresa Raquel Holanda Cipriano Saraiva', Cíntia Maria De Melo Mendes'.

${ }^{1}$ Uninovafapi University Center. ${ }^{2}$ Federal University of Piaui.

INTRODUCTION: Hypertension is a chronic disease characterized by high blood pressure levels in the arteries. It happens when the maximum and minimum pressure values are equal to or exceed $140 / 90 \mathrm{mmHg}$. High blood pressure is one of the main risk factors for stroke. According to the 2017 Surveillance of Risk Factors and Protection for Chronic Diseases by Telephone Survey (VIGITEL), the prevalence of self-reported hypertension went from $22.6 \%$ in 2006 to $24.3 \%$ in 2017 . OBJECTIVES: To describe the epidemiological aspects of hypertensive patients in Parnaíba (PI) and Campo Maior (PI) from 2010 to 2013. METHODOLOGY: A cross-sectional epidemiological study was conducted in Parnaíba and Campo Maior. The data originate from the Ministry of Health's Hypertensive and Diabetic Registration and Monitoring System, obtained from DATASUS / e-SUS. These values were categorized according to the relationship between hypertension and smoking, physical inactivity and overweight. Through this, percentages were obtained and used as object of study. RESULTS: The project comprised 1909 patients with hypertension in Campo Maior (PI), between 2010 and 2013, with the largest number of cases reported in 2011 (44.68\%). In Parnaíba, 2983 individuals with these characteristics were notified in the same period, with the largest amount observed in 2011 (42.30\%). In the city of Parnaíba, $18.13 \%$ of the patients with the condition are smokers. Similarly, $16.60 \%$ of patients are smokers in Campo Maior. Regarding physical inactivity, Parnaiba presents $40.09 \%$ of the total hypertensive patients. In Campo Maior, this value corresponds to $48.50 \%$. Regarding overweight, Parnaíba owns $27.08 \%$ of the total and Campo Maior $31.74 \%$. CONCLUSION: It is concluded that hypertension is a chronic disease of high prevalence, with many associated comorbidities. The analysis corroborated the relationship between hypertension and the variables studied. Therefore, it is necessary that policies be implemented for the monitoring, surveillance and control of this problem.

05.

\section{AUTOIMMUNE POLYGLANDULAR SYNDROME: A CASE REPORT}

Lucas Jesuíno Lobão Alencar Raulino Barbosa', Sarah Maria Monteiro Soares Costa de Holanda', Teresa Raquel Holanda Cipriano Saraiva', Társilla Carvalho Borges' ${ }^{1}$, Helena Moura de Carvalho ${ }^{1}$ and Aiana Camila Amâncio de Araújo Mendes ${ }^{2}$.

${ }^{1}$ UNINOVAFAPI University Center. ${ }^{2}$ Federal University of Piauí

INTRODUCTION: Autoimmune Polyglandular Syndromes (APSs) are defined by the coexistence of at least two autoimmune endocrine diseases. The joint appearance of these diseases depends on both genetic and environmental factors. In addition, APSs are subdivided into four subtypes (I, II, III and IV), which differ in the combinations of autoimmune diseases and the most common age of presentation. CASE REPORT: MJSD, 9 years old, female, with a history of alopecia areata since she was 4 years old, started on May 18th, a hypotension ( $85 / 60 \mathrm{mmHg}$ ) associated with nausea, vomiting, weight loss (6.5 kg in one month) and xerostomia. During hospitalization the presence of diabetic ketoacidosis was confirmed and the day after the complication the patient was diagnosed with autoimmune type 1 diabetes mellitus. Subsequent to the patient's stabilization, it was verified by routine exams, the existence of primary hypothyroidism (TSH: 87.3; FT4: 0.47) and, thus, it was possible to diagnose Autoimmune Polyglandular Syndrome (APS). After diagnosis, the approach adopted was insulinization through NPH insulin and regular insulin for application 30 minutes before meals, according to capillary blood glucose. In addition, levothyroxine (5omcg / day) was prescribed. After these measures, the patient improved her general condition and was discharged one week after hospitalization. FINAL CONSIDERATIONS: Autoimmune polyglandular syndrome is a rare disease, more prevalent in females and associated with genetic factors. Due to the chronic development of organ-specific autoimmunity, patients with the syndrome and their families should be informed about the early symptoms of the disease and undergo endocrinological assessments over time. Thus, early recognition of the syndrome is essential for its control.
06.

FALLOPIAN TUBE PROLAPSE AFTER HYSTERECTOMY: A CASE REPORT

Yasmine Maria Leódido Fortes1, Tayná Fernandes Jales1, and Laís Silva Fernandes 1.

' State University of Maranhão

INTRODUCTION: Fallopian tube prolapse is a rare complication after hysterectomy, with approximately 80 cases described. The reasons that may contribute are probably multifactorial: there should be a fallopian tube segment of sufficient length and mobility and a communication between the peritoneal cavity and the vagina should develop. As well as, it may result from a defective surgical technique, due to difficulties in closing the vaginal cuff or poor physical condition of the patient that interferes with wound healing. The symptoms are nonspecific and may include leukorrhea, transvaginal bleeding, dyspareunia, and pelvic pain. Definitive diagnosis will only be possible by histopathological examination of the lesion. Treatment should be individualized and can be performed vaginally, abdominally or laparoscopically. CASE PRESENTATION: Given this, we report the case of a 46year-old patient with leiomyomatosis. Evolving with prolapse of fallopian tube after vaginal hysterectomy. At the moment, the patient felt severe pelvic pain in addition to vaginal discharge. A new surgical intervention was then performed with anatomopathological examination that confirmed the diagnosis and is currently returning to initial symptoms at a lower intensity. CONCLUSIONS: The bibliographic study concluded that the fallopian tube prolapse after hysterectomy is a postoperative complication of rare multifactorial cause. Having the epidemiology justified by the infrequency of the coexistence of these conditions. It is also a difficult diagnosis to take into account an interval for non-regular onset of symptoms and an unspecific clinic. It is noteworthy that the results of surgical treatment of fallopian tube prolapse, regardless of the surgical route adopted, are satisfactory, with improvement of symptoms, with rare recurrence.

\section{EPIDEMIOLOGICAL STUDY OF ACUTE FLACCID PARALYSIS CASES IN THE STATE OF PIAUI FROM 2013 TO 2017}

Bárbara Louise Freire Barbosa', Helena Moura De Carvalho², Larisse Giselle Barbosa Cruz', Társilla Carvalho Borges², Teresa Raquel Holanda Cipriano Saraiva², Sarah Nilkece Mesquita Araujo Nogueira Bastos

${ }^{1}$ State University of Piaui. ${ }^{2}$ Uninovafapi University Center.

INTRODUCTION: Acute flaccid paralysis is defined as neuromuscular disease that affects the nerve, the neuromuscular junction plate or the muscle itself. They are characterized by rapid progression of muscle weakness, hypotonia, and deep or absent deep reflexes. Their primary onset is through Polio, an acute viral infectious disease.OBJECTIVES: To analyze the epidemiological profile of cases of acute flaccid paralysis in children and adolescents in the state of Piauí between 2013 and 2017.METHODS: This is a descriptive epidemiological study, whose data were obtained by consulting the SINAN (Notification of Disease Information System) database provided by the DATASUS / e-SUS system. The study population consisted of all cases of acute flaccid paralysis in children and adolescents, diagnosed and recorded from 2013 to 2017. In order to avoid notification delay errors, we decided to analyze the available data until 2017, last year. which contained the full data. The following variables were considered for analysis: age, gender and case evolution. From the data obtained from DATASUS, new tables were built through Microsoft Excel. Because it is a public domain bank, it was not necessary to submit the project to the Research Ethics Committee.RESULTS: During the study period, 58 cases were reported in the state of Piauí. of these, 45 were in children and 13 in adolescents. There was a predominance in the range of 5 to 9 years, with a total of 22 occurrences $(37.93 \%$ ). In the gender analysis, a greater number of notifications were detected in males, with a total of 36 cases $(62.06 \%)$. In evaluating the evolution of the cases, 32 patients presented cure without sequelae $(55.17 \%), 18$ patients cures with sequelae $(31.03 \%$ ) and blank 8 patients (13.79\%).CONCLUSION: This work concludes the relevance of the study of epidemiology, which is fundamental for the elaboration of public strategies to combat and prevent the diseases that affect society. 
08

\section{IDIOPATHIC CHRONIC EOSINOPHILIC PNEUMONIA: CASE REPORT}

Donizete Tavares da Silva'; Lucas Pereira de Carvalho'; Raul do Carmo Araújo웅 Maila Batista Barbosa de Moura²

Federal University of Piauí. ${ }^{2}$ University Hospital of the Federal University of Piauí.

INTRODUCTION: Idiopathic chronic eosinophilic pneumonia $(\mathrm{PECl})$ is a rare clinical entity characterized by alveolar and interstitial infiltration of eosinophils of unknown etiology, being more frequent in females (2:1). Its incidence is estimated to be less than 0.1 cases per 100,000 inhabitants. The clinical presentation is usually subacute or chronic, with complaints lasting more than one month before diagnosis is made. The most common symptoms are cough, dyspnea, chest pain, asthenia, fever and weight loss. The diagnosis of $\mathrm{PECl}$ is constructed by findings of pulmonary infiltrate in the chest $x$-ray associated with peripheral eosinophilia; unexpected evolution of pneumonic process; or presence of eosinophilia in the bronchoalveolar lavage (BAL). Pulmonary biopsy is the definitive method of diagnosis. Its prognosis is excellent and it shows an excellent response to corticosteroid therapy. The aim of the study is to report a case of idiopathic chronic eosinophilic pneumonia, an uncommon disease of special interes to pulmonology. CASE REPORT: A 39-year-old female patient from Batalha$\mathrm{PI}$, admitted for hospitalization with complaints of dry cough, asthenia weight loss, anorexia, chills and dyspnea on medium and small physical activity for 5 months. Reported lessening of cough after antibiotic use, and its return after discontinuation of the drug. Comorbidities: depressive disorder. Denies smoking. Physical examination of the respiratory tract with diffuse snoring and wheezing in the left hemithorax. Evolved during hospitalization with progressive increase of eosinophils. Spirometry: mild obstructive ventilatory disorder, unresponsive to bronchodilator. Chest CT: compatible with interstitial lung disease. Bacterial Sputum Culture: Pseudomonas aeruginosa. BAAR Search: No BAAR found. Lung histopathology: eosinophilic pneumonia. During the investigation no diagnosis of specific etiology was reached. Evolved with improvement of the initial condition after initiation of corticosteroid therapy with a Prednisone dose of $80 \mathrm{mg} /$ day, being discharged from hospital. FINAL CONSIDERATIONS: The diagnosis of PECI occurs after extensive investigation. In addition, although eosinophilia is usually detected by peripheral blood and/or BAL analysis, histopathological analysis may be the only diagnostic tool. The correct identification of $\mathrm{PECl}$ cases is essential for the specific treatment, with the possibility of complete regression of symptoms.

\section{EPIDEMIOLOGICAL ANALYSIS OF THE COW'S MILK POROTEIN ALLERGY} IN AN SPECIALIZED CLINIC IN TERESINA- PI

Natália Maria Marques Brito', Caroline Quaresma Tobias' Jackeline Dias Cunha Nogeuira², Thájara Fernandes de Sá Guimarães ${ }^{1}$ and Caroline Nogueira Paranhos ${ }^{1}$.

1 FACID/Wyden. ${ }^{2}$ IESVAP.

INTRODUCTION: Cow Milk Protein Allergy (CMPA) is the most common food allergy in pediatrics, affecting up to $1 \%$ of children in the first year of life. In Brazil, data on the prevalence and epidemiology of CMPA are scarce, making a close assessment of reality difficult. Due to the variety of symptoms, diagnosis is difficult for even pediatric doctors to make. OBJECTIVES: To evaluate the epidemiological distribution, prevalence and symptoms of CMPA in a specialized pediatric gastroenterology clinic in Teresina-PI. METHODS: The research was conducted in accordance with Resolution 466/2012 of the National Health Council and was initiated after the appreciation and release of the Research Ethics Committee of the Integral Differential College (approval number: 90560418.2 .0000 .5211 ). It is a descriptive research of quantitative and qualitative type. Data collection was performed in a pediatric gastroenterology clinic in Teresina-PI, through the analysis of electronic medical records, in which a questionnaire containing the following data was applied: gender, age at onset of symptoms and symptomatology at diagnosis. All patients treated between April 2016 and April 2018 were included, and medical records that did not contain the necessary data were excluded from the study, totaling 314 medical records that met the criteria. RESULTS: After analyzing the 314 medical records, it was found that $20.3 \%$ of the children attended were diagnosed with CMPA of these, $42.2 \%$ were female and $57.8 \%$ male. Regarding age profile, the following distribution was found: $34.4 \%$ were $0-2$ months, $37.5 \%$ were $3-5$ months, $7.8 \%$ were $6-8$ months, $1.6 \% 9-12$ months and $18.7 \%$ of the patients were older than 1 year at diagnosis. Analyzing the prevalence of symptoms at the time of diagnosis, it was found that: $79.7 \%$ of children had irritability at the time of diagnosis, $54.6 \%$ had diarrhea, $29.7 \%$ had skin symptoms, $25 \%$ respiratory symptoms, 20,3\% had regurgitation at diagnosis and only
$4.7 \%$ had constipation. CONCLUSION: Analyzing the data we concluded that the prevalence of CMPA was $20.3 \%$ in the studied population, where the most prevalent symptoms were irritability $(79.7 \%)$ and diarrhea $(54.6 \%)$. It is more prevalent in males $(57.8 \%$ ) and under 1 year old $(81.3 \%)$, more specifically between 3 and 5 months of life (37.5\%)

10.

\section{EOSINOPHILIC ESOPHAGITIS AS A DIFFERENTIAL DIAGNOSIS FROM NAUSEA AND VOMIT IN CHILDREN: A CASE SERIES}

Jackeline Dias Cunha Nogueira', Emanuella de Castro Negreiros Nogueira ${ }^{1}$, Beatriz Nogueira Maia Cavalcante ${ }^{2}$, Laurent Martial Clairet $^{3}$, Yasmim Fernandes Mota da Rocha ${ }^{3}$, Caroline Nogueira Paranhos ${ }^{3}$.

IESVAP. ${ }^{2}$ Uninovafapi. ${ }^{3}$ Facid Wyden.

INTRODUCTION: Eosinophilic esophagitis (EOE) is a chronic disease defined by the presence of eosinophilic infiltrate at a stratified squamous esophageal epithelium level that leads to esophageal dysfunction (food disorders, vomiting and gastroesophageal reflux symptoms), as well as dysphagia and food impactation. The pooled incidence rate is 3,7/100.000 person-years, being higher in adults when compared to children. The diagnosis is stablished by endoscopy and biopsy that reveal esophageal eosinophilic infiltrate at a level higher than or equal to 15 eosinophils per high-power field and no eosinophils in other digestive tube segments. CASE REPORT: All three cases reach pediatrics patients with age range starting at 3 years old, and that took at least 2 years to get diagnosed. The first case is a 9 years old male that sought the gastropediatric clinic complaining about vomiting and food refusal, associated to bolus, interrupted sleep to throw up and poor weight gain, he had already started treatment to Castroesophageal Reflux Disease (GERD), without symptoms improvement. The other two cases referred to female patients. The first one, 5 years old, with vomits and food refusal since birth, also treated for GERD, maintaining symptoms. At the last case, a two years old toddler, previously diagnosed with Cow's Milk Protein Allergy, came to the gastropediatric clinic with irritability, nausea and anorexia, with the symptoms bouncing back every time the GERD medication got suspended. Considering the clinical status and alarm signals founded in all three patients, all of them got an endoscopy where microscopical and macroscopical findings drove to the Eosinophilic Esophagitis diagnosis. Standard treatment with corticosteroids were introduced associated with proton-pump inhibitors, improving completely the symptoms and life quality for all three patients. CONCLUSION: The EoE is the second most common cause of chronical esophagitis, getting passed only by GERD, and is an emerging disease nowadays. Therefore, is necessary to inform the medical community about the importance of EOE and its differential diagnosis. Endoscopy and biopsy are fundamental for the diagnosis and follow up of these patients, allowing correct treatment and better life quality.

11.

EPIDEMIOLOGICAL STUDY OF HOSPITALIZATIONS FOR SKULL AND FACE BONE FRACTURES IN NORTHEASTERN BRAZIL

Murilo de Sousa Leal Rego Damasceno'; Fernando Sabino Silveira Garces', Antonio Isidoro de Sousa Neto ${ }^{2}$ and Noélia Maria de Sousa Leal ${ }^{3}$.

College FACID/DeVry. 2 Ermelindo Matarazzo Hospital. 3 College FACID/DeVry and Federal University of Piauí.

INTRODUCTION: Skull bone fractures represent a serious public health problem since they can cause head trauma, which is one of the leading causes of death and disability worldwide. OBJECTIVE: To describe the epidemiological profile of hospital admissions for fractures of skull and face bones in the Northeast region of Brazil. METHODS: This is a retrospective, longitudinal, descriptive and quantitative study that addresses hospitalizations for cranial fractures. Data were obtained from the SUS Hospital Information System database (SIH / SUS), according to age group, gender, Northeast state, and death rate, with the timeframe from 2008 to 2018. RESULTS: There were a total of 85,417 hospitalizations for fractures of the skull and facial bones in the Northeast during the analyzed period. The largest number of hospitalizations occurred in the state of Bahia $(21.90 \%)$, followed by Ceará $(17.31 \%)$. The state of Piauí recorded $9.16 \%$ of the tota hospitalizations, ranking fifth in the number of hospitalizations for cranial fractures. It is noteworthy that Piauí is the eighth state in the population of the Northeast region. The prevalence of hospitalizations was higher in males, with $83.96 \%$ of cases, compared to only $16.04 \%$ in females. The highest percentage of hospitalizations occurred in young adults, especially in the $20-29$ age group, which reached $35.38 \%$ of the total. The years with 
the highest percentage of hospitalizations were from 2013 to 2016, in which all reached a percentage of $9.6 \%$, while in 2017 and 2018 there was a reduction in this number, and last year this percentage fell to $8.32 \%$. The mortality rate due to skull and face fractures in the analyzed period was $0.87 \%$. The state with the highest mortality rate was Pernambuco, with $1.90 \%$, and the lowest rate was Piauí, with $0.35 \%$. CONCLUSION: Hospitalizations for skull and face fractures occurred especially with young male adults. Bahia was the northeastern state with the highest number of hospitalizations. Piauí presented a high percentage of hospitalizations, but a low mortality rate. Knowledge of the epidemiology of these fractures may contribute to the implementation of preventive programs aimed at reducing the number of hospitalizations, as well as possible sequelae and damage to the population.

12.

\section{COMPARISON BETWEEN CAUSES OF HOSPITAL ADMISSION RELATED TO PREGNANCY, BIRTH AND PUERPERIUM IN PARNAÍBA, PIAUÍ AND BRAZIL IN 2018}

Giovanna Stefanne Lópes Barbosa', Isabella Pires Gomes Mendes', Victor Augusto Soares Sotero', Raysa Maria Silva de Araujo $^{2}$, Nayana Alves de Brito Melo Okasaki ${ }^{1}$

${ }^{1}$ Federal University of Piaui - Campus Ministro Reis Velloso. ${ }^{2}$ IESVAP.

INTRODUCTION: The indices of the main causes of hospital admissions (HA) can help to understand the functioning of health networks and the prevention of injuries and preventable hospitalizations with integral care at all levels of health assistance. In the case of "Rede Cegonha", knowing the main causes of HA related to pregnancy, childbirth and the puerperium can be a way to evaluate the health of women in these phases. OBJECTIVES: To compare the main causes of hospitalization related to pregnancy, childbirth and the puerperium in Parnaíba, Piauí and Brazil, in 2018. METHODS Descriptive cross-sectional study in which the causes of HA related to chapter XV of ICD-10 "Pregnancy, childbirth and the puerperium" that occurred in 2018, in Parnaíba (PHB), Piauí (PI) and Brazil (BR) were analyzed by percentages, and compared with each other. Data were taken from the SUS Hospital Information System on the DATASUS platform. RESULTS: In 2018, there were $5,778,51,649$ and 2,474,382 HA related to Chapter XV of ICD-10 in Parnaíba, Piauí and Brazil, respectively. of these, the main cause was "encounter for full-term uncomplicated delivery" ( $52.6 \% ; 39.7 \%$ and $44 \%$ ). Excluding the generalist causes "other reasons for mother care related to the fetal and amniotic cavity, and possible birth problems" and "other complications of pregnancy and childbirth" that are in second and third place in the three levels analyzed, "spontaneous abortion" was second in hospitalizations in PHB (4.9\%). Meanwhile, when analyzing PI and BR "edema, proteinuria and hypertensive disorders in pregnancy, childbirth and the puerperium" were second, with 5.4 and $4.4 \%$, respectively. The other causes followed a similar distribution in all three areas. It is noteworthy that in PHB, HA were not accounted for "medical abortion", unlike PI (0.6\%) and BR (0.1\%). CONCLUSION: In general, hospitalization rates follow the same trend in Parnaíba, Piauí and Brazil, with some variations, and, as expected, the highest rate in the three spheres corresponds to "encounter for full-term uncomplicated delivery", indicating completely normal birth, the safest and most beneficial way for both mother and newborn. In addition, there is a high rate of "spontaneous abortion" in PHB, a trend not followed by the state and country, which is an injury that, in some cases, can be prevented with follow-up in primary care services, which may indicate a lack of integral care during pregnancy, childbirth and the puerperium.

\section{HOSPITALIZATIONS AND DEATHS FROM BREAST CANCER IN MEN IN} PIAUÍ FROM 2008 TO 2017

Giovanna Stefanne Lópes Barbosa', Isabella Pires Comes Mendes', Victor Augusto Soares Sotero', Raysa Maria Silva de Araujo $^{2}$, Caroline Camargo Bandeira da Silveira Luz ${ }^{1}$

${ }^{1}$ Federal University of Piauí - Campus Ministro Reis Velloso. ${ }^{2}$ IESVAP.

INTRODUCTION: Breast cancer (BC) is the most common cancer in the female population worldwide. However, about $1 \%$ of $B C$ cases affect men. Because it is rarer, there is no screening strategy. Thus, attention to signs and symptoms is essential. The male BC is most commonly presented as a painless nodule in the retroareolar region or by generally spontaneous unilateral papillary flow, although pain and skin retraction may also be present. OBJECTIVES: To describe the epidemiological profile of hospitalizations and deaths of men due to breast cancer in Piauí between
2008 and 2017. METHODS: Descriptive quantitative cross-sectional study. Hospital admissions and deaths from BC in men between 2008 and 2017 were analyzed for age and color/race of patients. Data were obtained through DATASUS, in Hospital Information System and the Mortality Information System sections. RESULTS: There were 94 hospitalizations by BC in men between 2008 and 2017 in Piauí. of these, $71.3 \%$ of patients were between 40 and 69 years old, with the 60 to 69 age group being the most prevalent $(27.7 \%)$. The stratum that presented the lowest prevalence was 15-19 years, with 2 cases $(2.1 \%)$. When considering the color/race of hospitalized patients, it was observed that $84 \%$ of patients were brown $6.4 \%$ white and $9.6 \%$ of patients did not have this recorded information. Regarding deaths, 21 were accounted for over the period analyzed. of these, no age group outperformed the others, with an average of 3.5 deaths $(16.7 \%)$ in the age group between 30 and 80 years or older. Regarding color/race, the highest percentage of deaths occurred with brown men $(61.9 \%)$, followed by whites $(23.8 \%)$ and blacks $(9.5 \%)$, with one patient death with race ignored. CONCLUSION: In Piauí, BC in men is more prevalent in those between 60 and 69 , especially browns. Regarding death, it occurred more with brown men without age prevalence, and the number of deaths related to $B C$ is significant, and may be related to late diagnosis in most men, with cancer being found in more advanced stages. Thus, the awareness of health professionals and the population about the possibility of male $B C$ and its consequences is important.

\section{WAARDENBURG SYNDROME: REPORT OF A TYPE III FAMILY CASE}

Marília Medeiros de Sousa Santos1, Caroline Baima de Melo², Elaine Crystine Vieira de Paiva ${ }^{3}$, Rayssa Alves de Araújoํㅜ, Mirla Ibiapina Leite'.

University Center UNINOVAFAPI. ${ }^{2}$ State University of Piauí. ${ }^{3}$ State University of Ceará.

INTRODUCTION: Waardenburg syndrome (WS) type I is a non-progressive auditory-pigmentary disorder comprising congenital sensorineural hearing loss and pigmentary disturbances of the iris, hair, and skin, along with dystopia canthorum (lateral displacement of the inner canthi). Affected individuals may have higher risk of: neural tube defects, cleft lip and palate, limb abnormalities, and Hirschsprung disease. Waardenburg syndrome is a rare autosomal dominant genodermatosis. The most frequent detections are dystopia canthorum, sinofris, broad nasal base, pigmentary alterations of the iris and skin, congenital deafness and frontal white wick. It can be found in 4 types, the most common being types I and II. OBJECTIVES: Report of a case of Waardenburg syndrome: case type III family. CASE REPORT: We report a case of Waardenburg type III syndrome in a male patient, 13-years-old with complaint of pruritus generalized for three months. The exam revealed clinical condition suggestive of atopic dermatitis, in addition to hypertelorism, bilateral dystopia canthorum, sinofris, iris heterochromia frontal white wick, articular contractures in upper limbs and hypochromic lesions in the thorax, dorsum and abdomen. The mother had a similar condition and both had congenital deafness. CONCLUSION: The patient was diagnosed with Waadenburg type III syndrome, in which there are musculoskeletal abnormalities of the upper limbs associated with the typical picture. The diagnosis of the syndrome allows a multidisciplinary follow-up of the patients. Most cases of this syndrome are accompanied by congenital deafness. Therefore, early diagnosis will certainly help in hearing rehabilitation, improving the capacity of developing hearing and communication skills of these individuals.

15. INITIAL APPROACH OF ACTIVE ULCERATIVE COLITIS: ROLE OF
CONVENTIONAL THERAPIES IN THE AGE OF IMMUNOBIOLOGICS. A
CLINICAL CASE REPORT Lucas Palha Dias Parente', Fábio Palha Dias Parente' ${ }^{1}$ Amanda Caroline Carneiro D'Albuquerque', Antônio Carlos dos Santos Silva Júnior ${ }^{1}$, Gustavo Ribeiro Palmeira ${ }^{1}$ and José Miguel Luz Parente ${ }^{2}$.

' Uninovafapi Medical School. ${ }^{2}$ Federal University of Piauí.

INTRODUCTION: Ulcerative Colitis (UC) is a chronic inflammatory disease that affects the mucosa and submucosa of the rectum and colon. The disease can have variable extension (E): proctitis, left colitis, or pancolitis; and severity ( $S$ ): mild, moderate, severe or fulminant. In this this clinical case report we aim to recognize UC in its moderate to severe activity and uncover treatment for promptly beginning the remission induction therapy. We follow ethical principles for scientific activity, such as the Informed Consent Form (ICF). CASE REPORT: The patient was a 50-year-old man with diarrhea 
(6 - 8 intestinal movements/day), hematochezia, intestinal cramps, and weight loss for four weeks. On exam, he was well-appearing with adequate perfusion and afebrile; the abdomen was diffusely tender to touch without distension, hepatosplenomegaly or peritoneal irritation. Laboratory tests were significant for leukocytosis $\left(16,460 / \mathrm{mm}^{3}\right)$, eosinophilia $(15 \%)$ and elevated C-Reactive Protein (CRP) $(25 \mathrm{mg} / \mathrm{dL}$ ). His initial diagnosis was thought to be infectious gastroenteritis or parasitic colitis and he was treated with ciprofloxacin, metronidazole and antiparasitics. Four weeks later, he only had slight improvement in his symptoms. A colonoscopy was obtained which showed moderate to severe pancolitis with histopathology consistent with chronic colitis in moderate activity. His disease activity score based on Mayo Clinic criteria was 10 points (moderate activity) and he was given a final diagnosis of UC with E3 extension (pancolitis) and S2 severity (moderate) based on Montreal criteria. He was started on prednisone 40 $\mathrm{mg} /$ day orally (14 days) and mesalazine MMX 4.8g/day orally. By week 12 of treatment his symptoms resolved (disappearing diarrhea, cramps and rectal bleeding) and laboratory tests values were significant for normal leukocytes $(7,226 / \mathrm{mm} 3)$, normal CRP $(5 \mathrm{mg} / \mathrm{dL})$ and fecal calprotectin 196 $\mathrm{ug} / \mathrm{g}$. A repeat ileocolonoscopy showed only mild inflammatory process in the distal rectum, without inflammatory activity in the other segments ( $E$ extension and S1 severity according to Montreal criteria). He was continued on mesalazine MMX $4.8 \mathrm{~g} /$ day, remission maintenance phase, with periodic clinical control. FINAL CONSIDERATIONS: The differential diagnosis of new onset colitis should include invasive enteroinfections and amoebiasis. Diagnosis should be confirmed by colonoscopy and severity stratification with clinical and endoscopic scores, to indicate appropriate therapy. Therefore, moderate UC should be promptly recognized to initiate conventional corticosteroid treatment for a few days, followed by oral mesalazine. In this case report, it was not necessary to use immunologic therapy.

16.

\section{BEHÇET DISEASE WITH INFLAMMATORY DISORDER OF THE CENTRAL NERVOUS SYSTEM: CASE REPORT \\ Antônio Carlos dos Santos Silva Júnior ${ }^{1}$, Gustavo Ribeiro Palmeira', Maynara de Carvalho Braga', Amanda Caroline Carneiro D'Albuquerque', Lucas Palha Dias Parente', Marconi Cosme Soares de Oliveira Filho'. \\ ' Uninovafapi University Center.}

INTRODUCTION: Behcet's Disease (BD) is a rare inflammatory condition characterized by recurrent oral and genital ulcers, usually painful, and various systemic manifestations (uveitis, arthritis, skin lesions, renal, cardiac, gastrointestinal, neurological or vascular involvement). Most clinical manifestations are secondary to vasculitis and neurological impairment occurs in less than $10 \%$ of cases. In describing the case, ethical principles were followed, such as the Informed Consent Form. CASE REPORT: A 22-year-old man was admitted to the emergency room with a complain of diplopia begun a day earlier. Has a depressive disorder since age 13 and uses olanzapine $15 \mathrm{mg} /$ day. Over the past year, she has sought medical attention on several occasions with reports of recurrent oral and genital ulcers, often accompanied by fever and generalized malaise, but without a definitive diagnosis. In the neurological examination, there was limitation of the right eye abduction, characterizing abducens nerve palsy, withou other noteworthy findings. Brain magnetic resonance imaging (MRI) showed increased T2 and FLAIR signal in the mesencephalic white matter, periaqueductal region and pontine tegment, with slight contrast enhancement, suggesting an inflammatory etiology lesion. CSF examination revealed normal opening pressure $(\mathrm{Pi})$ and normal cytochemistry ( $\mathrm{P}$ $20 \mathrm{cmH} 20$ / 3 leukocytes / protein $20 \mathrm{mg} / \mathrm{dL} /$ glucose $54 \mathrm{mg} / \mathrm{dL}$ ), as well as negative cultures. The erythrocyte sedimentation rate was increased $(45 \mathrm{~mm} / \mathrm{h})$ and serology and rheumatologic tests were negative. There were no signs of previous or current uveitis. Given this, the diagnostic hypothesis of Neuro-Behçet was made. The patient received pulse therapy with methylprednisolone (1g intravenously for 3 days), with complete improvement of diplopia. After starting maintenance therapy with prednisone, methotrexate and colchicine, ulcers disappeared. Control MRI performed after 6 weeks without changes. FINAL CONSIDERATIONS: There is no specific serological marker of the disease, being the diagnosis eminently clinical. Complementary examinations rule out other causes and evidence of inflammatory activity may be elevated. Patergia testing can be used as an auxiliary tool. The disease occurs with outbreaks and remissions and the goal of treatment is to suppress inflammatory activity, seeking to prevent irreversible organic damage.
17. OF PIAUÍ FROM 2015 TO 2018

Naiana Martins de Sandes1, Álvaro luiz Cutrim Costa Júnior ${ }^{1}$ Antonio Ferreira Mendes-Sousa², Sarah Nilkece Mesquita Araujo Nogueira Bastos ${ }^{2}$

FACID- WYDEN. ${ }^{2}$ Federal University of Piaui.

INTRODUCTION: Hanseniasis is a chronicle infectious dermatosis caused by Mycobaterium leprae that, if early detected and correctly treated, can be cured. According to the World Health Organization (WHO), hanseniasis can be classified in two types: paucibacillary (PB), presenting until 5 lesions, represented by the tuberculoid and undetermined forms of the disease; and multibacillary (MB), presenting more than 5 lesions, represented by virchowian and dimorfous forms of hanseniasis. OBJECTIVES: This study aimed to analyze the epidemiological aspects of the new hanseniasis cases in the state of Piauí from 2015 to 2018. METHODS: This is a descriptive epidemiological study, based on data obtained from the Notification Disease Information System (SINAN), available online through the DATASUS/e-SUS system. It was considered all hanseniasis cases confirmed and registered in the system from the year 2015 to the year 2018. The following variables were considered for the analysis: age, clinical form of hanseniasis, numbe of lesions and health macroregions. From data obtained on DATASUS, it was created new tables using Microsoft Excel software. As it was used public domain data, it was not necessary to submit the project to the Research Ethics Committee. RESULTS: In the studied period, 3,921 new cases were notified in the state of Piaui, with predominance in individuals between 50 and 64 years old, with 1,084 cases $(27.65 \%$ ) and 2,748 cases in individuals between 20 and 64 years old $(70 \%)$. About the clinical forms, the most common was the dimorfous form, presenting 1,560 cases $(39.78 \%)$, followed by indetermined ( 762 cases; $19.43 \%$ ), tuberculoid ( 527 cases; $13.44 \%$ ) and virchowian (522 cases; $13.31 \%$ ) forms. Five hundred and fifty (550) cases were ignored or not classified $(14 \%)$. Regarding the cutaneous lesions, it was recorded 1,115 paucibacillary cases $(28.44 \%)$ and 588 multibacillary cases $(15 \%)$, but this information was ignored in 2,218 cases $(56.56 \%)$. The health macroregions with highests numbers of cases were: Floriano, with 2,168 cases $(55.29 \%)$, Picos (632 cases; $16.19 \%$ ) and Teresina (477 cases $12.16 \%$ ). CONCLUSIONS: It is possible to conclude that young people (economically active age group) are the most affected with hanseniasis in Piaui, presenting the most severe forms of the disease. Among the health macroregions, Floriano calls the attention as the one with the highest number of new cases, highlighting the need of eficient public policies in the area for control and/or decrease of this disease.

18.

PHYTOCHEMICAL PROSPECTING AND EVALUATION OF THE GENOTOXIC EFFECT OF THE METHANOLIC FRACTION OF Poincianella bracteosa (Tul.) L.P. Queiroz. USING THE COMET ASSAY

Maria Gabriela Cavalcante Leal', Jéssica Ohana de Alencar Ferraz', Carlos Henrique da Silva Franco', Ronalt Cavalcante Morais Júnior ${ }^{1}$, Fabrício Pires de Moura do Amaral' ${ }^{1}$ and Pedro Marcos de Almeida'.

State University of Piauí.

INTRODUCTION: Poincianella bracteosa (Tul.) L.P. Queiroz. (Fabaceae), known as "catingueira", is a native species of the Caatinga and Brazilian Cerrado, widely used in popular therapy for the treatment of renal infection, intestinal pain and gastritis. However, there is still potential for compounds in $P$. bracteosa leaves to be genotoxic. OBJECTIVES: Evaluate the phytochemical prospecting and genotoxic potential of the methanolic fraction of $P$. bracteosa leaves (MFPb) in mice by comet assay. METHODS: $P$. bracteosa leaves were collected from EMBRAPA (Teresina-PI). The study was approved by the Ethics Committee on Animal Use (CEUA-UESPI $5117 / 2016$ ) with five groups ( $n=5$ ) of male Swiss mice (Mus musculus). The phytochemical profile was performed by colorimetric test to identify primary and secondary metabolites. MFPb was diluted with $1 \%$ dimethylsulfoxide (DMSO and distilled water) obtaining concentrations of 2,4 and $8 \mathrm{mg} / \mathrm{mL}$. A solution of $1 \%$ DMSO (via gavage) and cyclophosphamide (100 mg/kg; via intraperitoneal) were administered to the mice as negative (NC) and positive (PC) controls, respectively. The three MFPb concentrations were administered to mice via gavage. After $4 \mathrm{~h}$ and $24 \mathrm{~h}, 10 \mu \mathrm{L}$ of tail blood was collected from each animal and added to $100 \mu \mathrm{L}$ of low-melting agarose $(0.75 \%)$, which were distributed in two slides pre-coated with $1.5 \%$ common agarose. The slides were placed in lysis solution (18h) and then electrophoresed ( $15 \mathrm{~min}$.). They were stained with DAPI and analyzed unde fluorescence microscopy (400x). 50 nucleoids/slide were classified into five damage classes (o to 4 ) to assess the frequency and rate of damage. Data 
were analyzed by non-parametric test of Kruskal-Wallis and StudentNewman-Keuls a posteriori test $(p<0.05)$ in BioEstat 5.3. After $24 \mathrm{~h}$, all animals were sacrificed with ketamine $(100 \mathrm{mg} / \mathrm{kg})$ and xylazine $(16 \mathrm{mg} / \mathrm{kg})$ injections. RESULTS: The metabolites identified in MFPb were saponins, reducing sugars and phenols, which have important antioxidant activity due to their ability to eliminate reactive oxygen species (ROS). This activity is probably associated with the frequency and rate of non-significant damage at any of the concentrations tested when compared to NC. CONCLUSION: The results suggest that metabolites with antioxidant activity are related to the absence of MFPb genotoxicity, highlighting the importance of the use of the leaves as a phytotherapeutic potential by the population.

19.

\section{SCARRING OF THE LEAVES OF Himatanthus obovatus (Müll Arg.) Woodson}

Wesley Wagner dos Santos ${ }^{1}$, Aline Arruda dos Santos ${ }^{1}$, Claudia Roldão Barreto', Letícia Lima Bacelar', Wellington dos Santos Alves2 and Pedro Marcos de Almeida1

1 State University of Piauí.

INTRODUCTION: Himatanthus obovatus (Müll Arg.) Woodson, known as janaguba, is found in northeastern Brazil. Its leaves are used for hypertension, skin blemishes and an antitumor agent. However, studies on the healing action of leaves are still incipient. OBJECTIVE: To evaluate the intragroup healing effect of leaf ethanolic extract of $H$. obovatus (LEEHo) in mice. METHODS: Leaves of $H$. obovatus were collected in Teresina-PI and male Swiss mice (Mus musculus) came from the breeding stock of the State University of Piauí. The work was approved by the Committee on Ethics in the Use of Animals (CEUA-UESPI 00049/2017) with six groups (five animals per group). Dry leaves of $H$. obovatus were crushed, submitted to extraction in ethyl alcohol and rotated to the ethanolic extract. Then, ointments (LEEHo plus carbopol gel) were made at doses of 500,750 and $1000 \mathrm{mg} / \mathrm{kg}$. Carbopol gel, distilled water and Nebacetin ${ }^{\circledR}$ ointment were administered to the mice as negative control (NC), solvent control (SC) and positive (PC), respectively. Topical application of all the products was performed after $24 \mathrm{~h}$ of the surgical procedure, once a day, for 21 days with the aid of disposable swabs in sufficient quantity to cover the lesion. Wounds were recorded on days 0 (immediately after the surgical procedure), 7, 14 and 21 postoperative days. All photos were recorded with a pachymeter beside the animals. The images were recorded by means of a camera with image capture and for the analysis of the lesion area the program was used Image-J version 4.5.0.29 of Windows $98 / \mathrm{NT} / 200$. Data were analyzed by the Kruskal-Wallis test with Student-Newman-Keuls $(p<0.05)$ in the BioEstat 5.3 program. All mice were sacrificed and discarded after the experiment. RESULTS: On all evaluated days (0, 7, 14 and 21), the reduction of the area of the wound lesion was not significant between $\mathrm{NC}$ and SC. On days 7,14 and 21, the PC area reduction was significant in relation to NC. LEEHo showed no significant difference in lesion area when compared to $P C$ at $14^{\circ}$ ( 500 and $750 \mathrm{mg} / \mathrm{kg}$ ) and at $21^{\circ}(500,750$ and $1000 \mathrm{mg} / \mathrm{kg})$, which evidences the cicatrizing effect of LEEHO. CONCLUSION: The result evidenced that LEEHO was effective in healing in cutaneous lesions in the 14th and 21st days analyzed. In addition, microscopic studies are being evaluated to verify vascular proliferation, inflammatory cells, fibroblasts and collagen fibers.

20.

\section{DIFFERENTIAL DIAGNOSIS OF HEPATIC TUMORS: HEPATIC TUBERCULOSIS - CASE REPORT}

Paula Shelda da Fonseca, Luiz Filipe Ximenes da Silva', Augusto César Maia Rio Lima Silveira', Eduardo Salmito Ssoares Pinto² and Welligton Ribeiro Figueiredo'

' University Centre UNINOVAFAPI. ${ }^{2}$ Getúlio Vargas Hospital.

INTRODUCTION: Tuberculosis (TB) remains one of the main causes of morbimortality in the world today. Hepatic impairment in the extrapulmonary TB, though, is still highly uncommon. Hepatic TB isolated is an extremely seldom entity and only very rarely addressed by the relevant literature. It has more prevalence in immunodeficient patients, and its diffusion is directly related to the low social conditions faced by the population, typical of third-world countries. The occurrence of hepatic TB is usual in patients with severe immunosuppression and stricken with hepatomegaly and abnormal hepatic enzymes. Research indicates that, despite the resolution of the hepatic function in no more than six months, the mortality rate in one year remained high. Because this scenario in uncommon and the symptoms are unspecific, the diagnosis is difficult without a pathological analysis to confirm it, and, notwithstanding the advancements in imaging tests, the differential diagnosis of hepatic tumors still represents a big challenge. CASE REPORT: Male patient, 69 years old, with a history of pain in the right hypochondrium along with sporadic vomits over the last 30 days. He searched outpatient medical care where an ultrasound (US) revealed a voluminous hepatic lesion on the right lobe and was hospitalized in a public hospital of high complexity. The physical examination indicated flaccid abdomen painless during palpation, hyperpanism without visceromegalies, RHA + Abdominal US identified liver with augmented dimensions, regular contours and heterogeneous parenchymal echotexture due to the presence of a solid and rounded hyperechoic mass (presenting rapid contrast wash) and occupying a significant portion of the right lobe on segments V, VI and VII, measuring $9.4 \times 8.1 \mathrm{~cm}$. Alfalphetoprotein, CEA and CA19-9 were negative. Biopsy guided by TC was negative for malignancy. Unaltered blood count. Anti-HIV and serologies for hepatitis were nonreactive. Due to the persistence of the symptoms and the suspicious of Fibrolamellar Hepatocellular Carcinoma, a right hepatectomy with the duration of 4 hours without complications was carried out, and the patient was discharged from hospital on the 8th postoperative day. A Histopathology of the lesion confirmed hepatic tuberculosis. CONCLUSION: Hepatic TB is a rare disease with a difficult diagnosis. The big challenge involved in this operation is to differentiate it from hepatic tumors via imaging tests. Due to this complicated scenario, when there are fever, hepatomegaly and liver enzyme abnormalities, a hepatic biopsy must be carried out so that an antituberculotic therapy be initiated and complemented by surgery.

\section{INITIAL EXPERIENCE OF RADIOFREQUENCY FOR THE TREATMENT OF} LIVER TUMORS IN THE STATE OF PIAUÍ: A SERIES OF CASES

Paula Shelda da Fonseca, Luiz Filipe Ximenes da Silva', Augusto César Maia Rio Lima Silveira', Eduardo Salmito Soares Pinto ${ }^{2}$ and Welligton Ribeiro Figueiredo ${ }^{3}$

' University Centre UNINOVAFAPI. ${ }^{2}$ Getúlio Vargas Hospital.

INTRODUCTION: In 2018, primary liver cancer (CA) was the fifth leading cause of new cases of cancer, the third leading cause of death in the world and, in Brazil, $80 \%$ of those cases were related to Hepatocellular carcinoma (HCC). Furthermore, the liver is a very common target of metastasis from other tumors. Liver resection is considered to be the first choice when it comes to liver cancer, however, only 5 to $15 \%$ of those cases are submitted to curative resection, due to surgical contraindications. In those cases, radiofrequency ablation (RFA) appears as an interesting alternative, owing to its potential results which include the reduction of morbidity and mortality. CASE REPORT: The situations presented in the three first cases suggest the need of surgical indication due to liver metastasis of colorectal tumor. Via the use of an imaging test, the respective lesions have been identified. Woman, 70 years old, with 5 lesions, all with different sizes and on different segments of the liver (II - $2 \mathrm{~cm}$; III $-1.2 \mathrm{~cm} \mathrm{~V}-1.4 \mathrm{~cm}$; VI -2.9 $\mathrm{cm}$; VII $-1.9 \mathrm{~cm})$. The surgery was an RFA procedure of the lesions on segments II, III, V and VI, along with a Segmentectomy VII, totalizing 120 minutes. Woman, 57 years, with approximately 20 lesions, all with different sizes and on different segments of the liver, the biggest measuring: II-0.9 $\mathrm{cm}$; III-1.1cm; IV-1.4 cm; V-2cm; VI-2.1 cm; VII-1.3 cm and VIII-1.7 cm. The surgery performed was an RFA of 7 lesions along with a metastasectomy of the other lesions, totalizing 240 minutes long. Man, 58 years old, with 2 lesions with different sizes and on different segments of the liver (III-1.9 $\mathrm{cm}$; IV-2.3 cm) and 5 lesions on the right hepatic lobe $(V-1.3 \mathrm{~cm}$ e $2.4 \mathrm{~cm}$; $\mathrm{VII}-2.0 \mathrm{~cm}$ e $1.9 \mathrm{~cm}$; VIII-1.2 cm). The surgery performed was an RFA of 2 lesions on the left hepatic lobe along with a hepatectomy, totalizing 250 minutes long. Man, 74 years old, carrier of hepatitis C, cirrhotic Child-Pugh $B$, had simultaneously Gastric Adenocarcinoma and HCC. Through the imaging test, a lesion of $3.3 \mathrm{~cm}$ was identified on segment VI. The surgery performed was an RFA 1 lesion Segment VII along with a Partial Gastrectomy, totalizing 120 minutes long. CONCLUSION: In these cases, Radiofrequency and Intraoperative US were utilised, with no surgical complications. All the patients had a good postoperative evolution, necessitating in average 4 days of hospital internment for monitoring. The RFA, combined with a resection, have rendered possible the oncological treatment with maximal preservation of liver parenchyma, averting complications and prolonging the survival of the patients. 
22.
EPIDEMIOLOGICAL PROFILE OF PATIENTS IN STREET SITUATION WITH TUBERCULOSIS IN PARNAÍBA, TERESINA AND PIAUÍ, FROM 2015 TO 2018
Paulo César Monteiro Florêncio', Rebeca Matos de Almeida', Andressa Carvalho Pereira', Maria Isabel Pinheiro da Luz Esteves $^{1}$, Cristiane Feitosa Fonteles ${ }^{1}$ and Barbara Hamedy Carvalho Queiroz Aragão
State University of Piauí.

INTRODUCTION: Tuberculosis is an infectious and airborne disease that affects the lungs and / or may affect other organs and systems. Its etiological agent is Mycobacterium tuberculosis, also known as Koch's bacillus. The likelihood of a person being infected depends on exogenous factors. These include source case infectivity, duration of contact, and type of shared environment. Tuberculosis is a disease that can be prevented and cured, but still prevails in conditions of poverty and contributes to the perpetuation of social inequality. In Brazil, tuberculosis is a major public health problem, as we concentrate together with 21 other countries $80 \%$ of the global burden of tuberculosis. It has increased expression in immunosuppressed individuals, with homeless people being one of the groups most vulnerable to infection. OBJECTIVE: To analyze and compare the epidemiological profiles of tuberculosis in homeless people in the state of Piauí, between 2015 and 2018. METHODS: This was a quantitative, epidemiological, cross-sectional and retrospective study. The information was collected on the DATASUS platform of the Ministry of Health, from the TABNET program, in the Epidemiological and Morbidity - Cases of tuberculosis section. The data collected include all confirmed cases of tuberculosis in homeless patients notified in the SINAN, according to age group, gender, type of entry, licit or illicit drug use, and treatment outcome, between 2015-2018, registered in the city of Parnaíba, Teresina and the state of Piauí. Afterwards, the data were analyzed and tabulated using the Excel spreadsheet. RESULTS: During this period, in the state of Piaui, 61 cases of homeless patients with tuberculosis were found, 50 of them in Teresina and 4 in Parnaíba. Since 2015 the number of cases has grown, and 2018 had the highest number of cases (18). Tuberculosis predominated in the range (4059 years), with a total of 28 cases, and in males (75\%). Regarding drug use, they use alcohol, tobacco and illicit drugs, respectively, 55\%, 40\% and $65 \%$ of cases. Regarding the type of entry, $49 \%$ were new cases, $34 \%$ re-entry after abandonment and $6.5 \%$ relapse. The evolution to cure, treatment abandonment and death were the outcomes of $26 \%, 32.7 \%$ and $3.2 \%$ of the cases, respectively. CONCLUSION: Only in 2014 was the homeless population variable included in SINAN, which leads to underreporting of cases. This study found that men aged 40-59 years are the most affected. High rates of re-entry after abandonment and treatment abandonment are observed. Thus, there is a need for the creation of effective follow-up measures for this population, which enable adherence to treatment.

\section{EPIDEMIOLOGICAL PROFILE OF THE NUMBER OF DEBT DRYING IN THE STATE OF PIAUÍ FROM 2007 TO 2017}

Paulo César Monteiro Florrêncio', Tom Ravelly Mesquita Costa', Beatriz de Oliveira Nobre ${ }^{1}$, Alyne Silva Araújo ${ }^{1}$, Nadine Gabrielle dos Santos Rigamonte ${ }^{1}$ and Deodato Narcisio de Oliveira Castro Neto ${ }^{1}$.

' State University of Piauí.

INTRODUCTION: Death is drowning when there is no chance of resuscitation, with time for submersion or clear signs of death for more than one hour. It usually occurs due to unintentional causes and its risk factors are alcohol use, children, low socioeconomic status and greater exposure to the aquatic environment. About 500,000 people are estimated to be drowned in the world. However, data are uncertain due to underreporting, disappearance without confirmation of death and in cases of flooding. OBJECTIVE: To analyze the epidemiology of drowning death records in the State of Piauí between 2007 and 2017. METHODS: This is a quantitative, epidemiological, observational and cross-sectional study, based on data obtained from the DATASUS database, in the SUS Hospital Morbidity Section, of drowning death cases reported in the SUS Hospital Information System. in the State of Piauí, from 2007 to 2017. The variables used were: gender, age group, color / race and education. The collected data were tabulated in Excel. RESULTS: In the present study, it was found that during this period the state of Piaui reported 1,190 deaths from drowning, of which 287 in Teresina, 93 in Parnaíba and 24 in Luís Correia. 2016 had the highest number of cases (139). These deaths predominated in the age group 20-29 years, with a total of 237 cases, but were present in all ranges, from less than 1 year $(0.1 \%)$ to
80 years and over (0.3\%). And also in males ( $86.8 \%)$. Regarding years of schooling, there was a high prevalence in the ranges of 1 to 3 years $(25.5 \%)$ and 4 to 7 years $(25.9 \%)$. Regarding marital status and color / race, respectively, $58.3 \%$ were single and $71 \%$ brown. CONCLUSION: Thus, the cases of drowning death in the analyzed period have a higher incidence in Teresina, Parnaíba and Luís Correia and are influenced by several factors. In Teresina the high number of deaths due to drowning is due to the larger population contingent and the existence of rivers. Already the other two cities stand out for being coastal, favoring the increase of rates, despite the underreporting of cases in Parnaiba. There is still a predominance of males, as well as a greater relationship with the level of education.

\section{RELAPSE OF RARE INTRACEREBRAL MESENCHYMAL} CHONDROSARCOMA IN A YOUNG PATIENT: CASE REPORT

Vinícius Veras Pedrosa', Cristiane Fortes Napoleão do Rego'

'Federal University of Piauí.

INTRODUCTION: Primary Intracranial Chondrosarcomas (PIC) are extremely rare malignant bone and soft tissue tumors, accounting for less than $0.16 \%$ of all primary intracranial tumors. PICs usually originate at the base of the skull, with mesenchymal chondrosarcoma (MCS) being a histological subtype that predominates in the 4th and 5 th decades of life, affecting both sexes equally. Radical excision is the treatment of choice and postoperative adjuvant radiotherapy (RT) is the preferred treatment for remnant injury. CASE REPORT: A 31-year-old female patient had a three-year-old intracranial mass in the left front-parietal region. Biopsy of the lesion was performed and the histological sections were submitted to immunohistochemical study, which showed to be a biphasic mesenchymal neoplasia composed of small cell hypercellular area presenting oval nuclei with scarce cytoplasms, being permeated by hyaline cartilage islands. In addition, there were signs of descaling, findings consistent with MCS. Surgical resection was performed; however, postoperative adjuvant RT could not be employed due to complication by infected meningocele. After three years, the patient presented a new tumor formation in the left front-parietal region of dimensions $5.5 \times 4.0 \times 3.7 \mathrm{~cm}$. The histological study revealed to be MSC, class G3, suggesting possible recurrence. The patient was treated with new surgical resection and RT. Six months after relapse treatment, a magnetic resonance imaging of the skull was performed, which showed no evident expansive processes that could characterize possible relapse or residual base disease, and chemotherapy was unnecessary in view of this evolution. FINAL CONSIDERATIONS: Intracranial MCSS are rare entities and should always be remembered in the differential diagnosis of lesions located in the dura mater. The case in point reveals the harm of not performing adjuvant RT after surgical treatment, since the 5-year recurrence rate for patients with intracranial MCS treated with surgery alone is $44 \%$, which is markedly reduced to $9 \%$ after addition of adjuvant RT.

25. NATIONAL PROGRAM OF ACCESS AND QUALITY IMPROVEMENT OF PRIMARY HEALTH CARE (PHC): LEPROSY CONTROL ACTIONS IN PHC AT PIAUÍ UNDER TEAM'S PERSPECTIVE

Alyne Silva Araujo'; Francisco Mendes Frazão Junior²; Tauani Zampieri Cardoso ${ }^{3}$; Tom Ravelly Mesquita Costa'; Lucas De Carvalho Techi'; Osmar De Oliveira Cardoso ${ }^{1}$

' Federal University of Piauí. ${ }^{2}$ University Center UNINOVAFAPI. ${ }^{3}$ University of São Paulo.

INTRODUCTION: National Program of Access and Quality Improvement of Primary Health Care (NPAOI-PHC) was instituted in 2011 in order to improve primary health care (PHC) provided by the Brazilian Health System (SUS). $\mathrm{PHC}$ together with other health care network points is responsible for control actions of leprosy, such as new cases detection, polychemotherapy treatments, inabilities prevention and domestic contacts vigilance. OBJECTIVES: To describe control actions of leprosy developed by teams of Family Health Strategy (FHS) in Piauí on NPAQI - PHC context. METHODS: observational, cross-sectional and descriptive study. It was used data extracted from database of NPAQI - PHC's external evaluation of third cycle module II. 1071 FHS teams from Piaui that joined the program were interviewed from July to November 2017. It was chosen formulary's questions related to FHS actions in caring of people with leprosy. RESULTS New leprosy cases diagnoses is performed by $92 \%$ of interviewed teams. In contrast to affected users register, $17 \%$ of teams doesn't have it formally. About notification, $89 \%$ had the formularies, $84 \%$ filled them and $11 \%$ didn't. That impairs development and assessment of control and prevention politics' effectiveness of the illness in the country. Most of teams monitor 
users that were sent to referenced health services (94\%), reinforcing the role of PHC as a care coordinator. Active search is one of the resources of epidemiological vigilance used in control actions of leprosy. The NPAQI-PHC tool considers it in the following cases: symptomatics (skin lesions), leprosy's contact people, defaulting to treatment and abandonment. From overall, $92 \%$ of teams reported active search in all four cases; 7 teams only did it with skin lesions cases and 2 reported that didn't do it at all. CONCLUSION: Thus, it's evaluated as negative the number of teams that doesn't have register of users with leprosy (17\%). Another worrying data is that $11 \%$ of teams doesn't notify new leprosy's cases, impairing integrity of DATASUS data, and thus, health public policies. Regarding the monitoring of users, we see the fulfillment of the coordination attribute of PHC care in the care of people with leprosy in Piauí. And, finally, it is reinforced about the active search, an essential part in the control and prevention of leprosy.

26.

\section{EPIDEMIOLOGICAL ANALYSIS OF HOSPITALIZATIONS BY DENGUE BETWEEN 2014 AND 2017 IN PIAUÍ}

Cristiane Feitosa Fonteles', Andressa Carvalho Pereira', Paulo César Monteiro Florêncio', Maria Isabel Pinheiro da Luz Esteves', Rebeca Matos de Almeida' and Bárbara Hamedy Carvalho Queiroz Aragão'.

' Federal University of Piauí.

INTRODUCTION: Dengue is a viral acute infectious disease caused by four distinct serotypes belonging to the genus flavivirus. It is spread through the mosquito bite and its primary vector is the Aedes aegypt mosquito, predominant in tropical countries and in urban and semi-urban areas. OBJECTIVES: To analyze the epidemiological aspects of hospitalizations by dengue in the state of Piauí in the period from 2014 to 2017. METHODS: This is an epidemiological-retrospective study with a quantitative approach whose data source is the Department of Information Technology of the Unified Health System (DATASUS) of Ministry of Health. The research universe comprised 1204 cases of dengue hospitalizations notified in the Brazil's Information System for Notifiable Diseases (SINAN), analyzing the following variables: gender, age group, year of notification, city of notification and evolution of the disease. RESULTS: From January 2014 to December 2017, there were 1204 notified dengue hospitalizations in the state of Piauí. The prevalent age range was $20-39$, with $424(35.22 \%)$ hospital internments. It was observed that $657(54.57 \%)$ of the cases are of female patients, while $547(45,43 \%)$ are of male patients. The higher rate of hospital internments is concentrated in the year of 2014 , with 459 (38.12\%). Piauí's capital represents the higher number of occurrences, with 595 cases $(49.41 \%)$, followed by Barras and Parnaíba with $60(4.98 \%)$ and $46(3.82 \%)$, respectively. In $13(1.08 \%)$ cases the final outcome was death, in 967 $(80,31 \%)$ was the cure and 224 notifications had this information ignored. CONCLUSION: In this way, we can conclude that dengue causes a great burden to the health system, as the economic impacts and the negative repercussions it brings to society. Despite this viral infection is avoidable through simple sanitation, and eradication of the transmitting mosquito, used by the Government working together with the community. It was verified a high prevalence for some years in Piauí, proving flaws in prevention means and health promotion.

27.

\section{AUTOIMUNNE TYPE III C POLYGLANDULAR SYNDROME}

Bárbara Santos Accioly Calumby', Leticia de Melo Lustosa', Palloma Parry Carneiro', Louise Assunção Castro', Isabella Nunes Veloso' ${ }^{1}$, Adriano Rocha Alencar' ${ }^{1}$.

' Differential Integral College.

INTRODUCTION: The autoimmune polyglandular syndromes (PAS) are a heterogeneous group of diseases characterized by autoimmune activity against more than one endocrine organ, although non-endocrine organs may also be affected. In people with PAS, symptoms depend on which endocrine organs are affected and hormonal deficiencies do not always arise at the same time and may require years to develop. The type III PAS is defined by the presence of autoimmune thyroid disease (TDA) and one more autoimmune disease, excluding the adrenal gland. SPA III subtype $C$ develops when there is an association of vitiligo with TDA. CASE REPORT: A 60-year-old female patient, diagnosed with vitiligo for a long time (known as autoimmune disease), has medical follow-up at the Basic Health Unit. During routine consultation, she reported tachycardia and insomnia, which soon evolved to asthenia and excessive sleepiness, in addition to weight gain. Following TSH, free T4 and Anti-TPO results, she was diagnosed with
Autoimmune Hypothyroidism (Hashimoto's Thyroiditis). With the association of such diagnoses, she now has criteria for type III C SPA. In addition, the patient is also insulin-dependent diabetic. The possibility arises that its DM is type LADA (autoimmune form of diabetes mellitus that arises in adulthood), because it developed in a similar way: subacute hyperglycemia at very high levels, refractory to the use of oral hypoglycemic agents at maximum doses, so it is necessary to use different types of insulin for glycemic control. However, the measurement of peptide $C$, which would confirm DM I type LADA, was not performed. She is currently undergoing treatment with $\mathrm{T} 4$ hormone replacement, two types of insulin and regular consultations with dermatologists to monitor vitiligo. FINAL CONSIDERATIONS: The presence of autoimmune disease is a risk factor for other pathologies with such etiology. Thus, the report of the above case reinforces to the medical professional the need for screening of the most frequent autoimmune diseases in patients already affected by one or more diseases originated from the immune system disorder.

28.

\section{MORTALITY BY APPENDECTOMYS IN PIAUÍ IN 10 YEARS}

Maria Clara Mousinho Silva Rodrigues ${ }^{1}$, Aline Rodrigues Berrospi', Jéssica Ferreira de Moraes Brandão', Júlia Maria Soares da Silva', Nathalia Câmara Fontes Fernandes Torres ${ }^{1}$ and Welligton Ribeiro Figueiredo'.

${ }^{1}$ University Center Uninovafapi.

INTRODUCTION: Appendicitis is the main cause of urgent care for abdominal localized diseases (PETROIANU, 2012). The diagnosis is eminently clinical. In this sense, complementary exams are not necessary and help in the diagnosis. Appendectomy is the treatment of choice and should be immediate; It is often indicated for excision of the cecal appendix in acute and chronic inflammatory processes, with acute appendicitis being the most common indication. Appendicitis remains a major medical problem with high prevalence. OBJECTIVES: To determine the mortality of patients undergoing appendectomy in Piauí state, as well as to evaluate length of stay, age, sex and origin. METHODS: This qualitative and quantitative study was based on retrospective observation of patients from a public referral hospital in Urgência de Teresina, Piauí. To be performed, data were collected from all patients undergoing appendectomy from July 28,2009 to May 2, 2019, resulting in data analysis of 6607 patients. The analyzed variables obtained by means of the patients' medical records were: age, sex, origin, mortality and reoperation rate and length of stay. The collected data were entered and analyzed using simple descriptive statistics software. This study was approved by the Institution's Research Ethics Committee. RESULTS: We analyzed 6607 appendectomies performed in Piauí state, and it was observed that most were adults (51.43\%), male $(64.84 \%)$, coming from the capital Teresina itself $(48.48 \%)$, with an average length of stay of 3.49 days. Patients generally have only $1.12 \%$ of reoperations and a mortality rate of $0.46 \%$, which is considered low compared to other s study s literature Brazilian (2.67\%). CONCLUSION: It can be concluded that appendectomy performed in Piauí state was safe and has a lower mortality rate than the national average.

29.

\section{EPIDEMIOLOGICAL ANALYSIS OF THE PROFILE OF PATIENTS ADMITTED BY EXOGENOUS INTOXICATION BY SELF-MEDICATION IN PIAUI BETWEEN 2007 AND 2017}

Sarah Maria Monteiro Soares Costa de Holanda', Marianna Mendes de Barros ${ }^{1}$, Raíssa Martins de Oliveira Nunes ${ }^{2}$, Antonione Santos Bezerra Pinto ${ }^{2}$.

1 UNINOVAFAPI. ${ }^{2}$ IESVAP.

INTRODUCTION: Self-medication is the administration of medication without medical advice or prescription. Drug advertising through mass media is a stimulus, besides the ease of obtaining medicines without a prescription and the low purchasing power of the population, which makes it difficult to access the consultation. In addition, the tendency of immediate search for diseases. These factors have corroborated the growth of data related to selfmedication intoxication. OBJECTIVE: To analyze the epidemiological profile of cases of exogenous intoxication by self-medication intoxication in the state of Piaui from 2007 to 2017. METHODS: This is a descriptive and quantitative epidemiological analysis based on data available in the Information System for Notifiable Diseases (SINAN). Variables analyzed: age, gender, education level and evolution. Data were organized in spreadsheets using Microsoft Excel software. RESULTS: During the observed period, 275 cases of selfmedication poisoning were reported in Piauí. The data indicate a female 
majority, with $66.54 \%$ of cases. We highlight the age groups: between 20 and 39 years with a prevalence of $40.0 \%$, followed by 40 to 59 years in which $17.09 \%$ of the cases. As for the patient's education, this was underreported in $48.36 \%$. Regarding the evolution, the majority was the cure without sequelae, representing $80 \%$ of the cases, but with an important underreporting of $18.90 \%$. CONCLUSION: From the analysis, it is clear that the main groups of patients admitted for exogenous self-medication poisoning are young people and women. Also noteworthy is underreporting as a challenge for more effective tracking and monitoring of data. In addition, it is concluded that easy access and media stimulus to selfmedication are contributors to the indices. Therefore, control over the circulation of medicines should be sought, as well as public policies aimed at ratifying the danger of self-medication to society.

30.

PRENATAL USE OF SELECTIVE SEROTONIN-REUPTAKE INHIBITORS: RISK EVALUATION DURING FETAL GROWTH AND AFTER BIRTH

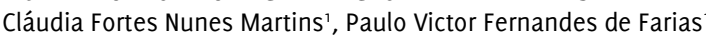
Suellen Guizini Pinheiro', Ticiana Maria Lúcio de Amorim', Leonardo Henrique Guedes de Morais Lima

' Federal University of Piauí.

INTRODUCTION: In the world, about $10 \%$ of pregnant women are diagnosed with some type of mental disorder, among those, depression stands out. The indication of drug treatment for pregnant women is a complex task, because it is known that psychofarmacologic agents and its metabolites pass through the placenta and this exposition can cause damage to the fetus health, besides they are classified in categories $C$ and $D$, according to the five categories system of teratogenic risk (A, B, C, D and X) created by the Food and Drug Administration. The selective serotonin reuptake inhibitors (SSRI) are the class of psychotropic drugs that compose the first line on depression treatment, acting on the blockage of presynaptic SERT transporters, increasing the extracellular serotonin concentration (5-HT) in the synaptic cleft. The data about the use of this drug class in pregnant women are limited and, therefore, the systematic review and meta-analysis may help on elucidating this question. OBJECTIVES: This work aimed to analyze studies developed on the use of SSRI by women during gestational period and its effect on the offspring's development. METHODOLOGY: The analysis was made from PubMed's and Bireme's database, looking for articles from 2008 to 2018, using the terms "Selective serotonin reuptake inhibitors" OR "SSRI" AND "Pregnancy" AND "Psychiatric disorders" AND "random clinical trial". The exclusion criteria applied were: not use of psychotropic drugs of SSRI's class and use of the drug on not pregnant population or not depressive pregnant women. Inclusion criteria were: presence of the terms previously determined, study developed from 2008 to 2018 and based on clinical trials. At first, 280 articles were obtained, which were analyzed and reduced to 87 , to 87 , based on exclusion criteria. RESULTS: With the research, 44 articles highlighted relation with teratogenicity, 14 cited autistic spectrum disorder, 6 was related with language disorders, besides 21 that mentioned multiple disorders, such as pulmonary hypertension, neonatal adaptation syndrome, motor disorders and others. In contrast, 18 of the articles reported no association with the drug and 25 of them were inconclusive or couldn't be analyzed. CONCLUSION: Based on the analysis, it is possible that exists a relation between the use of SSRI during pregnancy and the emergence of alterations in the offspring, such as autism and problems in fetal development. However, to confirm such affirmation, further and more detailed studies in systematic review and meta-analysis are required.

EPIDEMIOLOGICAL ANALYSIS OF CYTOPATHOLOGICAL EXAMINATIONS OF THE UTERINE CERVIX IN TERESINA-PI CITY, FROM 2016 TO JUNE 2019

Sarah Maria Monteiro Soares Costa de Holanda', Lucas Jesuino Lobão Alencar Raulino Barbosa', Társilla Carvalho Borges', Teresa Raquel Holanda Cipriano Saraiva', Helena Moura Carvalho'. 1 UNINOVAFAPI.

INTRODUCTION: Cervical cancer is a major public health problem and has been described as a condition that begins with progressive intraepithelial changes that may progress to an invasive cancerous lesion in 10 to 20 years. Therefore, it can be considered a preventable neoplasm due to the long preinvasive phase, when its precursor lesions can be detected through correct prevention, early diagnosis and appropriate treatment. The cervical cytopathological exam is considered the most effective and efficient exam to be applied collectively in screening programs. The World Health
Organization (WHO) recommends testing every three years for women aged 25 to 64 after two negative exams annually. OBJECTIVE: To analyze the epidemiological profile of cytopathological examinations performed in Teresina-PI. METHODS: This is a descriptive and quantitative epidemiological research based on data from the Department of Informatics of the Unified Health System (DATASUS), TABNET program. Variables analyzed: age group, squamous cell atypia and performed / altered exams. Data were organized in spreadsheets using Microsoft Excel software. RESULTS: During the observed period, 56,680 cervical cytologies were recorded in Teresina. Regarding the age group, women between 35 and 39 years old have the largest number of exams registered, indicating $12.91 \%$ of the total, followed by the 40 to 44 years old group, with $12.09 \%$. The altered exams represented $4.86 \%$ of the cases. Regarding squamous cell atypia, it was observed that the low-grade lesions (HPV AND CIN I) still overlap with other atypias, with the age range between 20 and 24 years being the one with the highest rates of this lesion, with $22,49 \%$. High-grade lesions (CIN II and CIN III) stand out in the age range 40 to 44 years, indicating $17.64 \%$ of cases, and secondly 35 to 39 years, with $15.83 \%$. High-grade lesion, which cannot exclude microinvasion and invasive squamous cell carcinoma, together represent $1.17 \%$ of squamous cell atypias. CONCLUSION: In this context, it is agreed that cervical cancer may have its incidence and mortality reduced by a properly organized screening program, added to the correct medical conduct. Therefore, early diagnosis through precursor lesions detected by oncotic colpocytology is of paramount importance. Therefore, this preventive outpatient examination should have its screening encouraged.

32.

"AGRESSÃO E DEFESA GAME": GAMIFICATION AS A TEACHING
STRATEGY IN PARASITOLOGY AND MICROBIOLOGY FOR STUDENTS OF
HEALTH

Maria Eduarda Mauriz Rodrigues', Eryka Borge Pinto', Natalya de Carvalho Lima', Anna Rasifa Soares Albuquerque', Ana Vitória Meireles Veiga' and Karina Rodrigues dos Santos'

Federal University of Piauí - Parnaíba.

INTRODUCTION: In response to the rapid evolution of health education, it was necessary to formulate strategies that stimulate students in the learning process. Camification is the mechanical use of games in non-game scenarios, and is a promising educational strategy. OBJECTIVES: To develop a playful teaching tool to facilitate learning about Parasitology and Microbiology content for health students. METHODS: This is an exploratory study through bibliographic research. The theoretical basis for the elaboration of the game consisted of materials already elaborated and published, composed mainly of books and scientific articles, as well as the authors' experience in the module "Bases of the Processes of Aggression and Defense II" of the Federal University of Piaui Medicine School. Couché paper was used to print the cards and trays. RESULTS: "Agressão e Defesa Came" is based on the activity of association between pathogens and the main systems affected by them, as well as the recognition of preventive measures for such infections. In this context, a game was created consisting of 3 boards and 48 cards ( 41 attack, 6 defense and 1 "Caution!"). The trays represent the human body and five of its systems. Attack cards represent pathogens that will attack one or more of the systems in question, in which there is a brief description of the agent and an indication of which system may be the target of the attack, while defense cards represent ways for preventing such attacks. The development of the game occurs by moves from attacking cards that damage systems, so that two successful attacks, which is, not defended by defense cards, destroy the system. The player who remains with at least one of the live systems wins the game. The card "Caution!" was created to prevent possible crashes during the match. CONCLUSION: The game was considered satisfactory both regarding the quality of the material and the aspect of the gameplay. It has been successful in addressing issues that are often considered complex in an easy and enjoyable way. The next step in making the use of this tool available to the community is to test it scientifically with health students as it is underway. It is also projected the suitability of the game to other audiences, such as elementary and high school students. 
33.

\section{PIAUIENSES, BY USE OF DRIED BLOOD SPOTS}

Emmanuelle Pessoa Costa', Hitalo Roberto de Araujo Coêlho', Danilo Rafael da Silva Fontinel', Fabiano Vieira da Silva and Liline Maria Soares Martins'.

' State University of Piauí.

INTRODUCTION: Hepatitis $B$ is a potentially fatal liver infection caused by hepatitis $B$ virus (HBV). It presents high transmissibility and impact on public health. Transmission can occur by parental, sexual and vertical routes, with perinatal transmission being one of the most important pathways and, also, the main form of transmission for newborns. The impact, if these are infected, is large, due to the high proportion of chronification of the disease. OBJECTIVES: To estimate the prevalence of hepatitis $B$ in pregnant women in Piauí and to identify the sociodemographic variables of the patients. METHODS: This is a retrospective, descriptive and Transversal study, previously approved by the Ethics and Research Committee of the State University of Piauí, Opinion N. 2.544.795. Data collection was performed in the laboratory of Piaui, using the database of the laboratory Environment Manager (LAC). We included pregnant women who underwent prenatal care in the period from January 2017 to December 2018. For the detection of HbsAg, Dried Blood Spots (DBS) were used by enzyme immunoassay (ELISA). RESULTS: We performed 46,018 tests on filter paper for hepatitis B in pregnant women. $98.5 \%$ of the samples were nonreactive. $0.05 \%(21)$ of the samples were reagents for hepatitis $B$ and $1.5 \%$ (682) were indeterminate or inconclusive. of these $110(16.1 \%)$ Repeated the examination. Referring to the provenance $34.7 \%$ of the pregnant women were from the central-North Piauiense mesoregion, $30.7 \%$ from the North Piauiense mesoregion, $18.3 \%$ from Southwest Piauiense and $16.3 \%$ from southeastern Piauiense. Regarding age group, $50.1 \%$ were between 20-29 years and $26.8 \%$ between 11-19 years. of the 21 reactive pregnant women, there was one case of syphilis co-infection. CONCLUSION: The hepatitis B virus had a prevalence of $0.05 \%$, a lower value than that found in other Brazilian studies. Among the tests that had an inconclusive or undetermined result only $16.1 \%$ repeated the test, being a limiting factor for the evaluation of the final outcome of the serological status of these pregnant women and for a good prenatal follow-up. In view of the repercussions that HBV can cause the life of the individual, the use of DBS represents a viable alternative to increase the access to serological tests during pregnancy and improve a quality prenatal follow-up, enabling the diagnosis and Clinical follow-up in early stages of infection and preventing vertical transmission.

CLINICAL-EPIDEMIOLOGICAL PROFILE OF CHRONIC HEPATITIS $C$ CARRIERS IN TREATMENT WITH DIRECT ACTION ANTIVIRAL AGENTS (DAAs)

Emmanuelle Pessoa Costa', Hitalo Roberto de Araujo Coêlho', Danilo Rafael da Silva Fontinel', Fabiano Vieira da Silva' and Liline Maria Soares Martins'.

$\checkmark$ State University of Piauí.

INTRODUCTION: Hepatitis C virus (HCV) infection represents an important public health problem due to its prevalence and severe consequences, and may cause chronic disease in up to $85 \%$ of the cases. Over the years, the risk of progression to cirrhosis occurs in $25 \%$ of the patients and, consequently, the development of hepatocellular carcinoma in $5 \%$ of these patients. In recent years, the emergence of new interferon-free therapies has meant a major breakthrough in the pursuit of the cure for hepatitis $C$. Direct-Acting antivirals (DAAs) are exclusively orally administered and have better cure rates (about $90 \%$ ), Shorter treatment time (12 to 24 weeks), few side effects and less negative impact on quality of life.OBJECTIVES: To describe the clinical and epidemiological profile of HCV patients undergoing DAAs therapy. METHODS: This is a retrospective, descriptive and Transversal study, previously approved by the Ethics and Research Committee of the State University of Piauí, Opinion N. 2.544.795. Data collection was performed in a pharmacy of exceptional medications in Piauí, using the database of the national system of Pharmaceutical Care Management (HORUS). We included patients who underwent treatment in the period from January 2017 to December 2018.RESULTS: Data from 237 patients were analyzed. $58.6 \%$ (139) were men and $41.4 \%$ (98) were women. The mean age was 53 years. The genotype $17.9 \%$ was $1 \mathrm{~A}, 37.8 \% 1 \mathrm{~B}, 0.4 \% 1 \mathrm{~A}$ and $1 \mathrm{~B}$, $2.9 \% 1,2.5 \% 2$ and $38.5 \%$ were Type 3 . The degree of fibrosis evaluated by liver biopsy and/or elastography revealed: $23.3 \% \mathrm{~F}_{1}, 27.4 \% \mathrm{~F} 2,20.5 \% \mathrm{~F}_{3}$ and $28.8 \% \mathrm{~F} 4$, being among the cirrhotic $53.8 \%$ Child-Pugh A, $26.9 \%$ Child-Pugh $B$ and $19.3 \%$ Child-Pugh C. The most commonly used therapeutic regimens were Daclatasvir + Sofosbuvir $(41.7 \%)$, Daclatasvir + ribavirin + Sofosbuvir
(31.2\%), Ombitasvir + Veruprevir + Ritonavir + Dasabuvir (11.4\%). 60.5\% of the patients were treated for 12 weeks and $39.5 \%$ for 24 weeks. Previous treatment had been performed in $8 \%$ of the patients. $4.6 \%$ of the patients were co-infected by HIV.CONCLUSION: The epidemiological analysis of patients in the treatment of hepatitis $C$ showed a predominance of men, older than 50 years and high prevalence of genotype 1, data consistent with the epidemiological studies found at national level.

35. CASE REPORT: EXTENSIVE TRAUMATIC HEMOVENTRICLE TREATED WITH FIBRINOLYTIC INSTILATION VENTRICULAR CATHETER

Marcos Vinícius Bertoldo Gomes', Matheus Rodrigues Corrêa' and Gustavo Sousa Noleto'.

' Federal University of Piauí.

INTRODUCTION: Intraventricular hemorrhage (HIV) is the appearance of blood in the ventricular system in the central nervous system. HIV can be spontaneous or traumatic. The clinical and radiological presentation of HIV is intracranial hypertension (ICH) and hydrocephalus, characterizing a neurosurgical emergency, requiring surgical intervention of ventriculostomy and ventricular drainage on an emergency basis. However, the high rate of ventricular catheter obstruction requiring multiple reinterventions makes this condition challenging. OBJECTIVES: We present a case of traumatic hemoventricular treatment treated with LVD fibrinolytic agent infusion, with excellent radiological evolution. METHODS: Patient, JAPS, male, 28 years old, motorcycle accident victim with helmet. Found unconscious on site, Clasgow Coma Scale 3, Vital signs of care were: blood pressure $150 \times 100$ $\mathrm{mmHg}, \mathrm{HR} 90$ beats per minute, $\mathrm{SO} 2$ 94\%; submitted to orotracheal intubation for airway protection and ventilatory support. Upon admission to the emergency department, Marshall III computed tomography (CT) of the skull showed massive panventricular hematoma with signs of hydrocephalus. An external ventricular shunt (LVD) catheter was implanted, through which $5 \mathrm{ml}$ of CSF was removed and $3 \mathrm{ml}$ of recombinant tissue plasminogen activator (rtPA) was infused $1 \mathrm{mg} / 1 \mathrm{ml}$. Then, the EVD system was kept closed for one hour, after which the EVD catheter was opened, communicating with the sterile collection bag. The patient was kept under drainage and continuous intracranial pressure monitoring. RESULTS: Serial neuroimaging examinations showed complete resolution of HV without signs of ventricular catheter occlusion. CONCLUSION: This alternative neurosurgical treatment for hydrocephalus and ICH in cases of extensive HIV by fibrinolytic agent via DVE controls the progression of hypertensive hydrocephalus and prevents ventricular catheter obstruction by conventional drainage clots. In addition, it can avoid the need for more invasive and costly surgeries, such as intraventricular clot removal craniotomy or cerebral endoscopy. It is important to emphasize the need to rule out risk factors and contraindications for the use of rt-PA, ruling out vascular lesions such as aneurysms or arteriovenous malformation. Further studies are needed to highlight its implications in terms of functional prognosis.

36.

EPIDEMIOLOGICAL ANALYSIS OF CONFIRMED CASES OF GESTACIONAL SYPHILIS INTE CITY OF PARNAIBA FROM 2015 TO 2019

Ariane Oliveira Dinato ${ }^{1}$, Eduardo de Carvalho Carneiro ${ }^{3}$, Gabriel Phelipe Dantas do Nascimento' and Nayana Alves de Brito Melo okasaki².

${ }^{1}$ Federal University of Piauí - UFPI-PHB. ${ }^{2}$ State University of Piauí - UESPI.

${ }^{3}$ Institute of Higher Education of Vale do Parnaíba - IESVAP.

INTRODUCTION: Syphilis is a sexually transmitted infection caused by Treponema pallidum. The prevalence of that infection, although reduced after the discovery of penicillin in the 1940s, became reemerging from the 1980 s and today has epidemic proportions. Syphilis, when infecting pregnant women, can result in vertical transmission of the disease. This condition, called congenital syphilis, is responsible for abortion, stillbirth and perinatal death in $40 \%$ of cases of children infected from untreated mothers. OBJECTIVES: This study aims to establish an epidemiological basis from data collected between 2015 and 2019 during prenatal care of pregnant women assisted by the municipal health network and estimates the prevalence of syphilis in pregnancy in the city of Parnaíba-PI. METHODS: Retrospective and documentary time series epidemiological study, with secondary data recorded from 2015 to 2019. All cases of gestational syphilis registered in the epidemiology sector of the Municipal Health Secretariat of the city of Parnaiba were used, using the base platform of SINANNET data. RESULTS: In 2015, 11 cases were registered, in subsequent years 25, 21, 28 and 18 , respectively, until 2019. The types of outcomes of gestational 
syphilis cases were analyzed. Thus, of the 103 cases reported in the database between 2015 and 2019, all reached cure after standardized treatment by the Ministry of Health. The most affected age group was around the 2nd and 3 rd decade of life. . The level of education was another factor analyzed, being the higher incidence in patients with 5 th to 8th grade of incomplete elementary school, summing 41 cases, demonstrating the close connection between education and health, because they have more education about the prophylaxis. The prevalence is higher in pregnant women of brown color, probably associated with the fact that the largest population in the city of Parnaiba is of brown race. CONCLUSION: From the epidemiological profile presented, it was possible to conclude that the municipality of Parnaiba presents some effective measures in the treatment of gestational syphilis, seen by the high cure rates of the patients. However, there is still a high incidence. Thus, it is necessary that public health policies are intensified and increased for a general control of gestational syphilis.

37

\section{OCCURRENCE OF GESTATIONAL SYPHILIS IN THE HALF-NORTH MACRO-REGION OF PIAUÍ IN THE PERIOD FROM 2014 TO 2018 - NA EPIDEMIOLOGICAL ANALYSIS}

Isadora Maria de Almeida Morais ${ }^{1}$, Eduardo Matos Linhares ${ }^{1}$, Laíse Cajubá Almeida Britto ${ }^{1}$

${ }^{1}$ Federal University of Piauí.

INTRODUCTION: Syphilis is a chronic systemic disease, usually transmitted by the sexual act, which has three phases. In Brazil, registered growth shows that the rate of detection of syphilis in pregnant women increased 4.9 times between 2010 and 2017, and there was also an increase in the number of cases of congenital syphilis. The VDRL is the most widely used test for screening during prenatal care and becomes positive 5-6 weeks after infection, which motivates the negativity in the first phase of the clinical manifestation of cancer. OBJECTIVES: To describe the occurrence of gestational syphilis (SG) in the middle-northern macroregion of Piauí, according to maternal data. METHODS: Epidemiological and descriptive study carried out through cases notified by the Notification Disease Information System (SINAN) in the period of 2014-2018 in the northern half of Piauí macro-region. It was considered the year and municipality of diagnosis, age group and maternal evolution. RESULTS: It was observed that in the period from 2014 to 2018 a total of 1,177 cases were reported in the Middle North macro-region of Piaui $(60.2 \%$ of the cases in the state of Piauí). The city with the highest incidence of SG is Teresina, with 1,014 reported cases $(86.2 \%)$. It was noticed that mothers $20-39$ years have $69.9 \%$ of notification. Additionally, there was a higher non-treponemic test (94.3\%) than a treponemic test $(71.02 \%)$. CONCLUSION: The diagnosis of SC is generally difficult because of the absence of symptomatology and the location of the signs are difficult to visualize. Thus, the performance and strengthening of prenatal care as a priority is useful to avoid such cases, ensuring prevention, diagnosis and appropriate treatment. In this perspective, the highest index observed in Teresina occurs because it is state capital and concentrates the largest population contingent. Although underage mothers are a risk factor for this infection, it was noticed that the majority of cases diagnosed were between 20-39 years, demonstrating the active search for adequate prenatal care in early treatment. Moreover, nontreponemic tests are more likely to result in false-negative results, depriving treatment; while the treponemic tests are more reliable and are less performed. It is emphasized that health prevention campaigns are essential to reduce these numbers and improve adherence to treatment. These two factors are intrinsically linked to a good bond in prenatal care and primary care for these patients.

38.

\section{RAYMOND SYNDROME IN AN ISCHEMIC BRAIN VASCULAR BRIDGE ACCIDENT}

Sharlla Layana Leite Mendes', Débhora Geny de Sousa Costa', Larissa Alves dos Santos Silva' and Tércio Luz Barbosa' 1 Federal University of Piauí.

INTRODUCTION: Brainstem injuries mostly affect structures related to the most diverse nerve functions, often causing varied and complex symptoms. In 1895, Raymond described an alternate syndrome (Raymond Syndrome) characterized by ipsilateral abducens palsy and contralateral hemiparesis. He located the lesion in the inferior portion of the bridge, the result of an ischemic event. Occlusion of a long penetrating artery causes paramedian cerebral trunk infarction, the associated involvement of cranial nerves depends on the level of the cerebral trunk at which occlusion occurred. Ipsilateral paralysis of the abducens (VI) and facial (VII) nerves are observed in the involvement of the pons. CASE REPORT: A 58-year-old female patient, hypertensive, former smoker, using losartan and hydrochlorothiazide, presented sudden right horizontal monocular diplopia, which improved with ocular coverage and associated left hemiparesis. On neurological examination, she presented VI cranial nerve palsy on the right and complete left hemiparesis. Cranial Computed Tomography showed hypodense area in the right frontal region, compatible with an undiagnosed old ischemic event, and Cranial Magnetic Resonance Imaging showed an area of diffusion restriction in the right bridge region, compatible with a recent ischemic event. CONCLUSION: Clinical recognition of Raymond Syndrome is critical for accurate topographic diagnosis of pontine tegmental lesions. The prognosis varies according to the degree of injury and response to treatment. Because it is a rare condition with variable clinical manifestations, its clinical diagnosis becomes difficult and complementary examinations become necessary.

\section{9.}

\section{EPIDEMIOLOGICAL PROFILE OF CONGENT SYPHILIS ACCORDING TO MATERNAL DATA AND PARTNER IN THE MIDDLE-NORTHERN REGION OF PIAU IN THE 2010-2018}

Mariana Veras Rocha Borges ${ }^{1}$, Isadora Maria de Almeida Morais', Laíse Cajubá Almeida Britto

${ }^{1}$ Federal University of Piauí.

INTRODUCTION: Congenital Systemic (SC) is a disease caused by vertical transmission of the pregnant child, is considered avoidable due to the form of mother contamination and access to treatment, and the occurrence is considered to be a failure in prenatal care. Even with the devices developed for the reduction of notification, it is considered a public health problem as to the persistence of the incidence of cases that can worsen causing commlications and perinatal/infant mortality. OBJECTIVE: To describe the occurrence of SC in the Northern Region of Piaui, considering the epidemiological data of the mother and partner. METHODS: An epidemiological study describing the cases reported by the Notification Information System (SINAN) in the period 2010- 2018 in the macro-region of Piauí North Environment was performed. Data were considered as maternal syphilis, prenatal care, partner treatment and local occurrence. RESULTS: The notification of 1,562 cases of congenital syphilis was observed in the middle northern region of Piaui during the period observed. It was noted that $40.1 \%$ of mothers were diagnosed with syphilis after delivery. Additionally, $83.2 \%$ underwent prenatal care. Regarding the treatment of the partner, $60.4 \%$ did not. Teresina had $99.3 \%$ of the reports. CONCLUSION: The high prevalence of CS indicates the need to strengthen prenatal care with priority, in order to contemplate pregnant women longitudinally with prevention, diagnosis and treatment. The index observed in the diagnosis of syphilis performed only during childbirth shows that, even with high adherence to prenatal care double - there is a notable failure in the transmission of health information. In this perspective, it also relates to the low treatment index of the partner, it is emphasized the ignorance of the severity of the disease while congenital to the baby and avoidable if treated appropriately. The high index observed in the city of Teresina occurs on account of being state capital. Thus, effective guidance to pregnant women and partners regarding SC aspects is essential, aiming at avoiding new infections and ensuring a higher quality prenatal care.

40. EVALUATION OF OVERLOAD OCCURRENCE AND ITS COMPLICATIONS
IN PATIENTS SUBMITTED TO SURGICAL HYSTEROSCOPY IN HU UFPI Gabryela Louzeiro Almeida Pedrosa ${ }^{1}$, José Matheus Guerra de Alencar Bastos ${ }^{1}$, Salatiel Martins Vieira', Lia Cruz Vaz da Costa Damásio ${ }^{1}$

${ }^{1}$ Federal University of Piaui.

INTRODUCTION: Hysteroscopy is a minimally invasive gynecological procedure in which an optical endoscopic lens is inserted through the cervix into the endometrial cavity usually using liquid distention media. Overloading occurs due to fluid absorption during the procedure with fluid overload with or without electrolyte imbalance. OBJECTIVES: Analysis of intraoperative and immediate postoperative findings and complications related to overload. METHODOLOGY: Analytical cross-sectional design, developed at the University Hospital of the Federal University of Piaui, from March to August 2017. The population included women who underwent surgical hysteroscopy at the service during the period mentioned. Data were collected in an electronic medical record. These were processed using IBM $₫$ SPSS $®$ Software, version 21.0, and descriptive statistics were calculated for 
quantitative variables; and frequencies, for the qualitative ones. In inferential analysis, data normality was verified by the Kolmogorov-Smirnov test. Student's t-test was performed for paired samples. All analyzes were performed at a significance level of $5 \%(\mathrm{p}<0.05)$. National and international ethical standards were met for conducting research involving human beings in accordance with Resolution 466/12 of the National Health Council (CNS) / Ministry of Health (MS). The research was authorized and approved by the Ethics Committee of the University Hospital of UFPI, under opinion 058023 / 2017. RESULTS: Excessive fluid absorption has an incidence of $0.2-0.76 \%$ and is a serious complication of surgical hysteroscopy. The diagnosis is made by the value of plasma osmolarity, which changes mainly by the variation of serum sodium and glycemia, consequent to the overload. Symptoms usually only occur when the circulation of fluid exceeds $3,000 \mathrm{~mL}$. Abrupt changes in serum sodium level can lead to altered mental status and progress to seizures, coma and death. There was a significant decrease in serum sodium levels before and after the surgical procedure, but without a sudden variation in levels nor a fall below $125 \mathrm{mEq} / \mathrm{L}$. Blood glucose had a significant increase in the mean. However, no statistically significant difference was identified between osmolarity means. CONCLUSION: There was a decrease in serum sodium and increased glycemia, but without changes in osmolarity.

\section{EVALUATION OF INTRA AND IMMEDIATE POSTOPERATIVE FINDINGS AND ITS COMPLICATIONS IN PATIENTS UNDERGOING SURGICAL HYSTEROSCOPY AT THE UFPI HU}

Gabryela Louzeiro Almeida Pedrosa 1, José Matheus Guerra de Alencar Bastos' ${ }^{1}$, Salatiel Martins Vieira', Lia Cruz Vaz da Costa Damásio $^{1}$

${ }^{1}$ Federal University of Piaui.

INTRODUCTION: Surgical hysteroscopy is the procedure of the lowest morbidity and mortality for the treatment of benign intrauterine pathologies. It has multiple indications, having rare complications and low morbidity and mortality. OBJECTIVES: The present study aimed to analyze the findings and complications in the intra and immediate postoperative period of patients undergoing surgical hysteroscopy. METHODOLOGY: Analytical cross-sectional design, developed at the University Hospital of the Federal University of Piauí-HUUFPI, from March to August 2017. The population included women who underwent surgical hysteroscopy at the Service during the period mentioned. Data on surgical technique, intraoperative and postoperative findings and complications were collected through the University Hospital Management Application (ACHU) available online. Study data were processed using IBM ${ }^{\circledR}$ SPSS ${ }^{\circledR}$ software, version 21.0, and statistics were calculated. All analyzes were performed at a significance level of $5 \%$ ( $p<0.05)$. National and international ethical standards were met for conducting research involving human beings in accordance with Resolution 466/12 of the National Health Council (CNS) / Ministry of Health (MS). The research was authorized and approved by the Ethics Committee of the University Hospital of the Federal University of Piauí, under opinion 058023/2017. RESULTS: The main intraoperative findings were endometrial polyps and submucous myomas. The complication rate found was $5.6 \%$, with $2.8 \%$ uterine perforation and $2.6 \%$ cervical laceration. Endometrial polyps are the most common benign endometrial pathology and submucous myomas are an important cause of uterine bleeding. The complication rates found are above those observed in the literature, where in general they remain below $1 \%$. Hidalgo shows a complication rate of $9 \%$, in a study conducted in a teaching center, which can be compared with the data from this study, where the complication rates are above the rates reported in the national and international literature, a fact that may be justified by the service being a teaching hospital and the procedure performed by residents in training and under supervision. CONCLUSION: The main intraoperative findings were endometrial polyps and submucous myomas, with a complication rate of $5.6 \%$, divided between uterine perforation and cervical laceration.

42.

INTERNAL ABDOMINAL HERNIA OF SMALL INTESTINE IN TRANSVERSE MESOCOLON IN YOUNG PATIENT WITHOUT PREVIOUS SURGERY: A CASE REPORT

Pedro Henrique de Souza', Andressa Carvalho Pereira', Priscylla Frazão Rodrigues', Yasser da Silveira Kruger ${ }^{1}$ and Eduardo Fernandes Arruda'.

${ }^{1}$ Federal University of Piaui.
INTRODUCTION: The paraduodenal hernias are rare conditions and they represent around $53 \%$ of the internal abdominal hernia cases. It occurs when the small intestine is contained inside the peritoneal cavity, adjacent to the Treitz ligament. Failure on the fusion between the mesentery and the parietal peritomy and by the bad intestinal rotation in the embryonic period are the cause of the hernia. Its particularity is due to long-term clinical condition, with challenging diagnosis and unspecific symptoms. One of the possible complications is the obstructive acute abdomen and, in these cases, the clinical manifestations include abdominal pain, such as colic, nausea, vomit and progressive abdominal distention. The diagnosis is generally closed through incidental found in image examinations or laparotomy. CASE REPORT: Reports a case of male patient, in his 18 years old, without previous surgeries or comorbidity. He showed clinical history of sudden abdominal pain of strong intensity, initiated 36 hours ago, in periumbilical region, colic-alike, without improvement factors or worsen at dorsal decubitus, associated with lots of emesis and hyporexia episodes. At his physical examination, he showed a regular general condition, reduced bowel sounds and flabby, diffusely painful to superficial palpation, abdomen. Furthermore, he referred intense pain during the rectus abdominis muscle extension. Laboratorial examinations and abdomen tomography were requested by the doctor. The blood count revealed remarkable changes in neutrophils and leucocytes values. A suggestive image of the obstructive acute abdomen due to intern hernia was found in the tomography, besides the swirl sign. The patient was, then, forwarded to an exploratory videolaparoscopy, which had to be converted into a exploratory laparotomy, due to the colon straps distension that prevented the reach of the diagnosis. The surgery showed an intern hernia in which the entire small intestine of the patient was encompassed by the transverse colon mesothelium, encapsulating it and, thus, determining an obstructive acute abdomen. After the procedure, there where significant improvement of the symptoms and the patient's quality of life. FINAL CONSIDERATIONS: The hernias are still common pathologies, with various symptoms and, in most cases, the treatment requires a surgery. In cases of colon straps distension, it is necessary to do the exploratory laparotomy, in order to reverse the intestine obstruction condition.

\section{INFANT MORTALITY: EPIDEMIOLOGICAL ANALYSIS OF AVOIDABLE CAUSES IN PIAUÍ BETWEEN 2013 AND 2017}

Ana Júlia Ribeiro de Sousa Castro', Marcela Maria Lopes Costa ${ }^{2}$, Leonardo Freire Jácome da Costa ${ }^{2}$ and José de Ribamar Ross².

${ }^{1}$ Federal University of Piauí. ${ }^{2}$ State University of Maranhão.

INTRODUCTION. The avoidable deaths are underestood like unnecessary episodes and preventable by medical technologies or that shouldn't happen. In the capital of Piaui, despite the advance to reduction of the infant mortality, is watched that the number stay high, being the majority envolved with avoidable causes. The necessary to explore this field gave margin to create the list of avoidable deaths causes in children under of 5 years old in order to serve like instrument in prevention and in detection of gaps in health care. OBJECTIVES: Analyse the clinical epidemiological profile of infant deaths from 0 to 4 years old by avoidable deaths registered in Piauí in the period of 2013 to 2017. METHODS. Descriptive exploratory transverse study. Collect was realized on TABNET site with the target of group prevalence datas employing variables: health region, death year, sex, color/race, mother's age, mother scholarity and birth weigh. The data were combined in spreadsheet of Microsoft Excel. RESULTS. In the determined period, 2.595 deaths were registered from 0 to 4 years old by avoidable causes in Piauí, being distributed in 137 etiologys and 1.022 causes in reasons not cleary avoidable. The most prevalent causes are fetus and newborn affected by maternal affections with 451 cases $(17,38 \%)$, followed by maternal complications in the pregnancy with 295 cases $(11,36 \%)$, and neonatal infection, besides congenital viral hepatitis and congenital rubella syndrome, with 227 cases $(8,74 \%)$. The victims were, mostly, from the health region of Entre Rios, with 1.105 deaths $(42,58 \%)$. The peak of the cases happened in 2013 with 536 notifications $(20,65 \%)$. The marjority of infant deaths were masculine, $1.457(56,14 \%)$, and brown color/race, with 1.904 notifications $(73,37 \%)$. As for the mother's age, 20 to 24 years old predominated, with 595 cases $(22,92 \%)$, while the maternal scholarity concentrated in 8 to 11 years, with 989 notifications $(38,11 \%)$. The preponderant birth weigh oscillated from 500 to 999 grams, with 678 deaths $(26,12 \%)$. CONCLUSION. The knwoledge of the infants deaths profile by clearly avoidable causes allows map the main causes and propitiates the elaboration of more accurate strategies to avoid the occurrence of death in this region. This way, is essential the investment in a better quality in 
maternal-infant health care. Promoting, thus, the declin in demonstrated epidemiological index.

44 .

CLINICAL-EPIDEMIOLOGICAL PROFILE OF CHRONIC HEPATITIS C
CARRIERS IN TREATMENT WITH DIRECT ACTION ANTIVIRAL AGENTS
(DAAS)
Emmanuelle Pessoa Costa', Hitalo Roberto de Araujo Coêlho',
Danilo Rafael da Silva Fontinel', Fabiano Vieira da Silva' and Liline
Maria Soares Martins'.
'State University of Piauí.

INTRODUCTION: Hepatitis C virus (HCV) infection represents an important public health problem due to its prevalence and severe consequences, and may cause chronic disease in up to $85 \%$ of the cases. Over the years, the risk of progression to cirrhosis occurs in $25 \%$ of the patients and, consequently, the development of hepatocellular carcinoma in $5 \%$ of these patients. In recent years, the emergence of new interferon-free therapies has meant a major breakthrough in the pursuit of the cure for hepatitis $C$. Direct-Acting antivirals (DAAs) are exclusively orally administered and have better cure rates (about 90\%), Shorter treatment time (12 to 24 weeks), few side effects and less negative impact on quality of life.OBJECTIVES: To describe the clinical and epidemiological profile of HCV patients undergoing DAAs therapy. METHODS: This is a retrospective, descriptive and Transversal study, previously approved by the Ethics and Research Committee of the State University of Piauí, Opinion N. 2.544.795. Data collection was performed in a pharmacy of exceptional medications in Piauí, using the database of the national system of Pharmaceutical Care Management (HORUS). We included patients who underwent treatment in the period from January 2017 to December 2018.RESULTS: Data from 237 patients were analyzed. $58.6 \%$ (139) were men and $41.4 \%$ (98) were women. The mean age was 53 years. The genotype $17.9 \%$ was $1 \mathrm{~A}, 37.8 \% 1 \mathrm{~B}, 0.4 \% 1 \mathrm{~A}$ and $1 \mathrm{~B}$, $2.9 \% 1,2.5 \% 2$ and $38.5 \%$ were Type 3 . The degree of fibrosis evaluated by liver biopsy and/or elastography revealed: $23.3 \% \mathrm{~F}_{1}, 27.4 \% \mathrm{~F}_{2}, 20.5 \% \mathrm{~F}_{3}$ and $28.8 \%$ F4, being among the cirrhotic $53.8 \%$ Child-Pugh A, $26.9 \%$ Child-Pugh $B$ and $19.3 \%$ Child-Pugh C. The most commonly used therapeutic regimens were Daclatasvir + Sofosbuvir $(41.7 \%)$, Daclatasvir + ribavirin + Sofosbuvir $(31.2 \%)$, Ombitasvir + Veruprevir + Ritonavir + Dasabuvir (11.4\%). 60.5\% of the patients were treated for 12 weeks and $39.5 \%$ for 24 weeks. Previous treatment had been performed in $8 \%$ of the patients. $4.6 \%$ of the patients were co-infected by HIV.CONCLUSION: The epidemiological analysis of patients in the treatment of hepatitis $C$ showed a predominance of men, older than 50 years and high prevalence of genotype 1, data consistent with the epidemiological studies found at national level.

45.

SEROLOGICAL SCREENING FOR HEPATITIS B IN PREGNANT WOMEN IN PIAUIENSES, BY USE OF DRIED BLOOD SPOTS

Emmanuelle Pessoa Costa', Hitalo Roberto de Araujo Coêlho', Danilo Rafael da Silva Fontinel', Fabiano Vieira da Silva and Liline Maria Soares Martins ${ }^{1}$

State University of Piauí.

INTRODUCTION: Hepatitis $B$ is a potentially fatal liver infection caused by hepatitis $B$ virus (HBV). It presents high transmissibility and impact on public health. Transmission can occur by parental, sexual and vertical routes, with perinatal transmission being one of the most important pathways and, also, the main form of transmission for newborns. The impact, if these are infected, is large, due to the high proportion of chronification of the disease. OBJECTIVES: To estimate the prevalence of hepatitis $B$ in pregnant women in Piaui and to identify the sociodemographic variables of the patients. METHODS: This is a retrospective, descriptive and Transversal study, previously approved by the Ethics and Research Committee of the State University of Piauí, Opinion N. 2.544.795. Data collection was performed in the laboratory of Piauí, using the database of the laboratory Environment Manager (LAG). We included pregnant women who underwent prenatal care in the period from January 2017 to December 2018. For the detection of HbsAg, Dried Blood Spots (DBS) were used by enzyme immunoassay (ELISA). RESULTS: We performed 46,018 tests on filter paper for hepatitis B in pregnant women. $98.5 \%$ of the samples were nonreactive. $0.05 \%(21)$ of the samples were reagents for hepatitis $B$ and $1.5 \%$ (682) were indeterminate or inconclusive. Of these $110(16.1 \%)$ Repeated the examination. Referring to the provenance $34.7 \%$ of the pregnant women were from the central-North Piauiense mesoregion, $30.7 \%$ from the North Piauiense mesoregion, $18.3 \%$ from Southwest Piauiense and $16.3 \%$ from southeastern Piauiense. Regarding age group, 50.1\% were between 20-29 years and $26.8 \%$ between $11-19$ years. of the 21 reactive pregnant women, there was one case of syphilis co-infection. CONCLUSION: The hepatitis B virus had a prevalence of $0.05 \%$, a lower value than that found in other Brazilian studies. Among the tests that had an inconclusive or undetermined result only $16.1 \%$ repeated the test, being a limiting factor for the evaluation of the final outcome of the serological status of these pregnant women and for a good prenatal follow-up. In view of the repercussions that HBV can cause the life of the individual, the use of DBS represents a viable alternative to increase the access to serological tests during pregnancy and improve a quality prenatal follow-up, enabling the diagnosis and Clinical follow-up in early stages of infection and preventing vertical transmission.

\section{RATHKE'S POUCH CYST: A CASE REPORT}

Pedro Henrique de Souza', Andressa Carvalho Pereira', Priscylla Frazão Rodrigues', Yasser da Silveira Kruger $^{1}$ and José Carlos Martins Costa. ${ }^{1}$

1 Federal University of Piaui.

INTRODUCTION: The Rathke's pouch cysts are wounds present in $12 \%$ to $33 \%$ of all autopsies with patients that have normal hypophysis. In general they are asymptomatic, although sometimes they can cause endocrinological disturbs and compression of the optic chiasma, due to the improvement of the cyst size. Women are the most affected and the common symptoms are: amenorrhea, galactorrhea, visual disturbs and cephalalgia. The casuistry of the cyst is still unknown, however, there were an increasing of the diagnosis with the improvement of the image examinations precision. CASE REPORT: Reports a case of a Japanese male patient, in his 61 years old, that had symptoms of asthenia, libido's loss, erectile dysfunction, myalgia depression, retro-ocular pain with visual field reduction, left amaurosis and cutaneous pallor. The laboratorial examinations indicated hypopituitarism, with considerable hormonal alterations on LH, FSH, Prolactin, TSH, ACTH total testosterone, free testosterone, androstenedione, S-DHEA, ICF-I somatomedin C and SHBC. In the magnetic resonance examination of the skull and sella turcica, cystic wound characteristics were found, seen in sellar region with suprasellar extension, measuring around $1,7 \times 2,8,1,7 \mathrm{~cm}$ $(\mathrm{AP} \times \mathrm{CC} \times \mathrm{LL})$, determining compression and skull displacement of the optical chiasma. Among the considered diagnosis hypothesis, the possibility of a Rathke's pouch cyst was highlighted. Because of that, a transsphenoidal surgery was indicated, which was performed by experienced professionals: an otolaryngologist and a neurosurgeon. During the procedure, specimens of the cyst epithelium and of the cyst itself were collected and forwarded to the anatomopathological examination, confirming the preoperational diagnosis. After 5 months of the procedure, the patient is already doing his own routine activities without disturbance, the pituitary hormone levels returned to normal and he had great improvement of physical disposition, of skin coloration and of libido. FINAL CONSIDERATIONS: The formation of Rathke's pouch cyst is still not well defined and the clinical condition is generally asymptomatic, which hampers the clinical and radiological diagnosis. The precision of the image examinations allowed the diagnosis of this report, configuring the transsphenoidal surgery as the most recommended in these cases.

\section{EPIDEMIOLOGICAL PROFILE OF VIRAL HEPATITIS IN THE STATE OF PIAUÍ FROM 2014 TO 2018 \\ Alâine de Macedo Cavalcanti'; Brenda Alves dos Santos'; José Clemente Flores Ultimo'; Nadjla Andreya Alves Gonçalves Macêdo Cipriano $^{1}$ \\ ${ }^{1}$ Federal University of Piaui.}

INTRODUCTION: Viral hepatitis are diseases caused by different etiological agents, with primary liver tissue tropism, which have similar epidemiological, clinical and laboratory characteristics, but with important particularities. Viral Hepatitis are common, sometimes severe infectious conditions, that develop with liver inflammation and necrosis. They are most commonly caused by hepatitis A, B, C, D and E viruses. According to the Ministry of Health, from 1999 to $2017,587,821$ confirmed cases of viral hepatitis have been reported in the Notified Health Information System (Sinan) in Brazil. OBJECTIVE: To describe the epidemiological profile of Viral Hepatitis in the State of Piaui from 2014 to 2018. METHODOLOGY: A descriptive epidemiological study was conducted with the reported cases of Sinan viral hepatitis in the period from 2014 to 2018 in Piauí. gathering information from the DATASUS database. RESULTS: In the period analyzed, 854 cases were reported in the state. When compared to other Northeastern states, Piauí only represents $3.7 \%$ of notifications. Approximately $24 \%$ of cases occurred in $2014,18.4 \%$ in $2015,17.4 \%$ in $2016,18.2 \%$ in 2017 and $22 \%$ 
in 2018. Regarding the age group affected, the one with the highest prevalence was $40-59$ years, followed by 20-39 years, representing $33.8 \%$ and $28 \%$, respectively. Regarding the etiological classification, Hepatitis B and $C$ had a higher prevalence with $36.5 \%$ and $37.7 \%$, respectively, followed by hepatitis A with $19 \%$. Regarding the forms of infection, $11.2 \%$ occurred during sexual intercourse, $15.2 \%$ occurred through contaminated food and water, but $54.3 \%$ of the cases do not have notification with the specific cause. CONCLUSION: Over the past five years, viral hepatitis in Piauí has had a low number of reports compared to other Northeastern states. These values alert to a possible underreporting of the disease in the state, warning of the importance of greater epidemiological control of this pathology. In addition, there are problems regarding the totality of information about the source of infection. The data presented can be used in the performance of health professionals and managers and thus strengthen surveillance programs.

\section{8}

\section{FEMALE EPIDEMIOLOGICAL PROFILE OF A LOCAL COMMUNITY FROM PICOS - PI}

Cabrielly Costa do Nascimento ${ }^{1}$; Emanuel Victor Cordeiro da Costa Silva'; Iago Cardim Santana'; Gigliolla de Moura Macêdo²; Fatima Regina Nunes De Sousa ${ }^{3}$; Ticiana Maria Lúcio de Amorim³. ${ }^{1}$ Federal University of Piauí. ${ }^{2}$ Basic Health Unity Cecília de Sousa Neri.

INTRODUCTION: Picos is a city located in the center-south region of Piauí state, with a population of 73414, in which 38353 are women. The women's age rate is concentrated between 15 and 19, following the initiation of the sexual life (around 15 years old). With the beginning of sexual activities, the Health Ministry recommends that Pap smears exams must be done, without cost for the patient in the Public Health System (SUS), aiming to reduce the rate of cervical cancer. This pathology occupies 3 rd position in Brazil $(8,1 \%)$ and 2nd position in Piauí $(26,19 \%)$ among types of cancer with major incidence. Professionals of the Basic Health Unity (UBS) in Picos are capable of collect cytopathological samples to Pap tests, and that was the reason this unity was chosen for this study. OBJECTIVES: This work aimed to analyze the total rating of cytopathological exams collected at the UBS Cecilia de Sousa Neri, and the predominating diagnostics. METHODS: The study was conducted from 01/2017 to 06/2019 at the Basic Health Unity Cecília de Sousa Neri, located in the São José district of the city of Picos- PI. The personal data of the patients were kept in closure. RESULTS: The health unit consists of 2 groups of professionals from different areas and 1 supporting health unity (NASF). Medical care is encompassses 2106 people, which 938 are male and 1168 are female. The total of female patients assisted during analysis was 339 , corresponding to $29 \%$ of the total users. On the professional group 1, the largest number of women tested has 50 to 54 years old $(17,6 \%)$, followed by 45 to 49 years old women $(14,2 \%)$ and, with the same percentage, 35 to 39 and 20 to 24 years old (11,3\%). For the group 2 , the largest number of women was concentrated in the range of 20 to 24 and 30 to 34 years old, both with $(11,8 \%)$. The diagnoses showed an elevated rate of inflammation on women in both groups, with $57,8 \%$ (group 1) and $42,7 \%$ (group 2), followed by infections by Gardnerella sp. (2,3\% group 1 and $4,2 \%$ group 2 ). CONCLUSION: The data presented in this study shows that the search for the tracking exam, in a 2 -year period, is lower $(29 \%)$ than preconized by SUS, even in the age range of higher danger of developing the cervical cancer. With this result, it is possible to develop public politics that encourage the search and periodical tests of this important exam for the prevention of the cervical cancer.

49.

\section{EPIDEMIOLOGICAL ANALYSIS OF MENINGITIS IN THE STATE OF PIAUÍ FROM 2014 TO 2018}

José Clemente Flores Ultimo'; Alâine de Macedo Cavalcanti'; Brenda Alves dos Santos'; Tercio Luz Barbosa ${ }^{1}$

${ }^{1}$ Federal University of Piaui.

INTRODUCTION: Meningitis is an inflammatory condition that involves the membranes (meninges) that cover the brain and spinal cord. It presents as a syndrome of fever, headache, nausea or vomiting and sometimes meningeal signs with inflammation in the subarachnoid space that is evidenced by cerebrospinal fluid (CSF) pleocytosis. It may have infectious causes, such as bacteria, viruses, parasites, or may be associated with autoimmunity, cancer, or drug reactions. In Brazil, meningitis is a disease of immediate compulsory notification, carried out within 24 hours for municipal and state surveillance, being the responsibility of health services, public or private, and health professionals, to notify every suspected case.
OBJECTIVES: This study aims to perform an epidemiological analysis of Meningitis in the state of Piauí from 2014 to 2018. METHODS: This descriptive and epidemiological study was conducted from the reported cases of meningitis in the state of Piauí in the Brazilian System. Disease Information Notice (Sinan). Data were collected in July 2019, but refer to the period 2014 to 2018 , based on information collected in the DATASUS database. Data analysis was performed using Excel spreadsheet software. RESULTS: A total of 881 cases were observed, and the year with the highest number of confirmed cases of meningitis was 2014 with $n=222$ cases, representing $25.19 \%$, followed by a downward line with reduction. annual percentage of $8.13 \%$ by 2018 . A rate of $7.26 \%$ of the total cases were classified as Ign / White. The number of confirmed cases in children and adolescents represents $43.92 \%$ of cases. Regarding the etiology of confirmed cases of meningitis, $29.17 \%$ were classified as unspecified meningitis (MNE), 38.47\% classified as viral meningitis (MV) and $9.19 \%$ meningitis by other etiology (MOE). Regarding the evolution of cases according to age group, in children and adolescents the case fatality rate was $5.68 \%$, the highest case fatality rates are in the age group of 20 to 39 years and 40 to 59 years, with $15.69 \%$ and $18.07 \%$ respectively. In meningitis due to other etiology (MOE), the case fatality rate was $35.80 \%$, the highest among all etiologies. CONCLUSION: It can be concluded that meningitis remains a disease of very clinical and epidemiological relevance in the state of Piauí, but some points in its conduction and diagnosis are still flawed, leading to underreporting, incomplete diagnoses and possibly contributing to therapeutic failures affect the evolution of cases.

50.

\section{USE OF ACETYLCYSTEINE IN TRICHOTILLOMANIA TREATMENT: CASE REPORT}

Leticia de Melo Lustosa', Bárbara Santos Accioly Calumby', Fernanda Ayres de Morais ${ }^{2}$ and Adilson da Costa ${ }^{2}$.

' Facid Wyden College. ${ }^{2}$ Dermatologist.

INTRODUCTION: Trichotillomania (TTM) is an impulse control disorder consisting, among other criteria, of recurrent hair pulling behavior. It results in noticeable hair loss and secondary alopecia. N-Acetylcysteine, recent in treatment, brought significant reduction of symptoms of the disease. In this paper, we report a case of TTM with excellent response to its use. CASE REPORT: A 19-year-old female patient attended the outpatient clinic accompanied by her mother, who reported her daughter's hair loss since the age of 7, progressively progressing to areas of hair thinning. She also mentioned that her daughter was pulling and fidgeting a lot when she was anxious. No comorbidities, previous treatment and/or medication use. Dermatological examination: areas of capillary rarefaction predominating in parietal regions, sparing occipital region. Capillary rods of various sizes and some coiled appearance. No changes in the scalp region and the follicular region. Dermoscopic examination: multiple abnormalities of the capillary axis with no significant changes in the pericollicular area broken hair, trichoptilose, black dots, flame hair and coiled hairs]. Scalp biopsy: 32 pilosebaceous units ( 18 in the anagen phase, 11 in the catagen phase, and 5 in the telogen phase), dilated, some devoid of hairy structures, with marked eosinophilic border, mild peripheral fibrosis, and moderate peripheral mononuclear infiltrate. The hair matrix exhibited pigmentary incontinence and numerous apoptotic cells. With the diagnosis of TTM, she was referred for psychiatric treatment and started acetycysteine 1200mg at night for 30 days. At 60 days, there was improvement of the picture, with hair growth and reduction of the area of rarefaction. FINAL CONSIDERATIONS: TTM differs from benign and transient hair-pulling conditions seen in the early years of life. The shame of symptoms observed in patients and the lack of knowledge by health professionals contribute to the underdiagnosis of this disorder. It must be identified early before possible clinical complications and psychosocial repercussions. N-Acetylcysteine is effective in restoring extracellular glutamate concentration and decreasing oxidative stress, reducing compulsive behaviors. In this study, the drug was well tolerated with no adverse events.

\section{EPIDEMIOLOGICAL PROFILE OF HOSPITALIZATIONS DUE TO SKULL AND FACIAL BONES FRACTURES IN PIAUI - BRAZIL}

Fernando Sabino Silveira Garces ${ }^{1}$, Murilo de Sousa Leal Rego Damasceno', Antonio Isidoro de Sousa Neto ${ }^{2}$, Noélia Maria de Sousa Leal ${ }^{3}$

${ }^{1}$ Facid Wyden. ${ }^{2}$ Ermelino Matarazzo Public Hospital. ${ }^{3}$ UFPI and Facid Wyden.

INTRODUCTION: Skull and facial bone fractures are among the main lesions on polytraumatized patients nowadays. These types of fractures are usually related to cranioencephalic trauma which stands out as an important cause 
of death or physical and mental deficiency or disability, being one of the neurological pathologies that has more impact on people's quality of life and being surpassed only by stroke. OBJECTIVES: Describe the epidemiological profile of hospital admissions for skull and facial bone fractures and ascertain its distribution according to sex, age, county and death rate. METHODS: It is a retrospective, longitudinal, exploratory, descriptive and quantitative study. The data was collected through the database from Hospitalar Information System / SUS (SIH/SUS) according to age range, sex, county of residence and death rate, having, as a time period, the years of 2008 to 2018. RESULTS: It was obtained a number of 7,826 admissions for skull and facial bone fractures at the state of Piauí, during the years of 2008 to 2018, being the largest number registered in 2018 with 937 cases. Between the total cases registered, the prevalence was bigger on the male sex with $79 \%$ of the cases, and the most affected age was between the ages of 20 to 29 years old. Between the analyzed years, the capital Teresina has shown the biggest percentage of cases $(88.10 \%)$, followed by the county of Floriano $(6.78 \%)$ and Parnaíba $(2.47 \%)$. The mortality rate of the state during the years of 2008 to 2018 due to skull and facial bone fractures was of $0,35 \%$ having the county of Parnaiba with the biggest mortality rate of the state $(1.05 \%)$. The average of days of hospitalization for patients with skull and facial bone fractures in the state of Piauí was 4 , 4 days. The biggest averages were registered on the county of Barras ( 7.4 days) and Floriano (7.1 days). CONCLUSION: With this study it was possible to conclude that the epidemiological profile of hospitalizations due to skull and facial bone fractures was in adults between 20 and 29 years old and from the male sex. Besides, it's noticed that the number of cases of skull fractures increased considerably during the years on the state. It's worth mentioning that the knowledge of the epidemiological profile of these types of fractures can contribute for the implantation of prevention programs and to improvements on attendance, reducing possible sequels and minimizing costs.

52.

EPIDEMIOLOGICAL ANALYSIS OF CONFIRMED CASES OF GESTATIONAL SYPHILIS IN PARNAÍBA, TERESINA AND PIAUÍ, FROM 2015 TO 2018 Authors: Andressa Carvalho Pereira', Cristiane Feitosa Fonteles' Paulo César Monteiro Florêncio', Maria Isabel Pinheiro da Luz Esteves' ${ }^{1}$, Rebeca Matos de Almeida', Bárbara Hamedy Carvalho Queiroz'.

' Federal University of Piauí.

INTRODUCTION: Syphilis is a sexually transmitted infection with prevalence rate and high vertical transmission, and of compulsory notification, caused by the bacterium Treponema pallidum. During the pregnancy it is defined when the pregnant woman show clinical evidence and/or non-treponemal reagent serology, performed prenatally or at the time of the delivery or curettage. Thus, pregnant women not or incorrectly treated can transmit it transplacentally, causing fetal sequelae to the newborn. OBJECTIVES: To make epidemiological analysis of confirmed cases of gestational syphilis in Piauí, Teresina and Parnaíba during the period of 2015 to 2018. METHODS: This is an epidemiological, quantitative and retrospective study, which data source is the Disease Notification Information (SINAN), available by the DATASUS. Cases were analyzed using the following criteria: race, age group, education, FU where prenatal care was performed, clinical classification and diagnostic tests in Parnaíba, Teresina and in Piauí between 2015 and 2018 RESULTS: During this period, in Piauí, 1723 cases of gestational syphilis were reported, of this total 892 were reported in Teresina and 87 in Parnaíba. There was a progressive increase in the number from 2015, and, in 2018 had the highest number (612). The cases were predominant in the people of color $(72.1 \%)$ and between the ages of 20 and 39 years old $(68.1 \%)$. In terms of education, they were illiterate, had incomplete elementary school, incomplete high school and complete higher education, $0.75 \%, 37.8 \%, 18.6 \%$ and $1.2 \%$ respectively. Of the total, 1607 women had prenatal care in the state of Piauí $(93.2 \%)$ and 7 performed out of state. This information was ignored in $6.3 \%$ of cases. Regarding the clinical classification, there was a predominance of the latente form $(31.8 \%)$, followed by the primary $(27.4 \%)$ the tertiary $(17.1 \%)$ and the secondary $(5.5 \%)$. For the diagnostic tests, were performed non-treponemal serological tests in $89 \%$ of the cases, in which $95.5 \%$ had reactive result. The treponemal tests were performed in $62.7 \%$ of the cases, in which $94.2 \%$ had reactive result. CONCLUSION: It has been shown that although syphilis is a curable and treatable disease, there is still an increase in the number of cases that it is a major factor to continue spreading transmission, including vertical transmission. Therefore, the strengthening of strategies is essential on promoting health and prevention of gestational syphilis, such as health education and proper prenatal care.
53.

\section{LUMBAR SYMPATHECTOMY FOR ISCHEMIA TREATMENT IN PACIENT WITH SYSTEMIC SCLEROSIS: A CASE REPORT}

Andressa Carvalho Pereira', Pedro Henrique de Souza', Priscylla Frazão Rodrigues' ${ }^{1}$, Yasser da Silveira Krüger ${ }^{1}$, Elias de Carvalho Magalhães Neto'.

Federal University of Piauí.

INTRODUCTION: The lumbar sympathectomy consists in the sympathic nervous chain removal located in the abdômen, in the anterolateral portion of the lumbar vertebrae. This procedure, although being out of use, it is stil indicated in the treatment of some pathologies like the Raynaud disease, chronic peripheral arterial insufficiency, arterial inflammatory diseases and hyperidrosis. The physiological basis of sympathectomy are the imediate paralytic vasodilation, the phenomenon of hemometakinesia and the circulation development. Even being a proven safe procedure, some complications can be manifested, like bleeding of lumbar vessels and damage to structures adjacentes to the sympathetic chain. CASE REPORT: Reports a case of a male patient, 45 years old, that came to the hospital showing cyanosis of left pododactyl, with distal pulse presence. After the vascular surgeon's evaluation, vasospastic phenomenon have been identified and the treatment with the use of corticoid, Cilostazol and oral anticoagulant have been initiated, observing the ischemy reduction and the clinical improvement. The patient was submitted to distal phalanx of the second left pododactyl debridement, due to necrosis presence in this region. During the outpatient follow-up, some sugestive signs chronic reumathic disease have been noticed, such as arthralgia, myalgia, telangiectasias, sclerodactyly and Raynaud phenomenom. The evaluation of a Rheumatologist has been asked, which, after the clinical condition analysis and antinuclear factor test (ANA), had reached the diffuse cutaneous systemic sclerosis. Around two months after, the patient had returned with a new vascular episode, post right lower member trauma, along with serious involvement of the pododactyls, with amputation risk. The patient possessed relative counter indication of angioplasty, due to the vasculitis clinical condition. Therefore, the lumbar sympathectomy had been chosen by the vascular surgeon, which was proved to be an effective alternative for the case. The patient had pain, cyanosis and coldness reduction postoperatively. He has also been treated by the multiprofessional team since then, present significant clinical improvement. FINAL CONSIDERATIONS: Despite the lumbar sympathectomy be an antique technique and conflicting results, it proved to be and effective and safe alternative for the ischemic case described, having a significant improvement of the symptoms.

\section{ENDONASAL SURGICAL TREATMENT ENDOSCOPIC GH-SECRETINC PITUITARY ADENOMA: CASE REPORT}

Marcela Maria Lopes Costa', André Lages Conçalves Castelo Branco $^{2}$, Vinícius Ribeiro de Arêa Leão Costa' ${ }^{1}$, Lara Raissa Matos Carvalho', Wyliver Barkyn Saunders Rocha Tavares², Ricado Marques Lopes de Araujo3.

State University of Maranhão. ${ }^{2}$ University Uninovafapi. ${ }^{3}$ New York Presbyterian Hospital.

ABSTRACT: Acromegaly is an uncommon and debilitating disease due to overproduction of growth hormone $(\mathrm{CH})$ and, as a consequence, insulin-like growth factor, which leads to an extreme development of the skeleton and soft tissues. The insidious aspect of acromegaly and the lack of knowledge of the population make the diagnosis usually made about 10 years after the appearance of the first signs and symptoms. In Brazil, considering a population of 190 million people, it is estimated that $570-760$ new cases of acromegaly occur every year, on a total prevalence of 7,600-3,300 cases. Most of the cases result from $\mathrm{CH}$-secreting pituitary adenoma, with a mass effect on the noble structures nearby the sellae. Thereby, it is emphasized the importance of this reaction, measuring the high morbidity and the reduced life expectancy associated with the complications involved with $\mathrm{CH}$ / IGF-I excess and the possibility of effective treatment using a minimally invasive method. CASE REPORT: A 61-year-old female patient presented with decompensated diabetes mellitus, acromegalic facies and reduced visual acuity. Laboratory tests revealed levels of IGF-1 685.7 and $\mathrm{GH}$ 43.2. After, it was performed a sella turcica MRI, where a $1.8 \times 1.2 \times 1.4 \mathrm{~cm}$ lesion was identified. Endonasal endoscopic treatment was also taken, whose histopathology showed $\mathrm{CH}$-secreting pituitary adenoma. Post-surgery, the patient evolved on a satisfactory performance, without complaints, and with significant improvement in glycemic and visual control, and continues in multidisciplinary follow-up. Six months after surgery, the control lab demonstrates proper glycemic control and GH: 2.2, IGF-1: 240 and 
postoperative MRI shows no residual injury. FINAL THOUGHTS: We described a case of $\mathrm{CH}$-secreting pituitary adenoma treated by minimally invasive access with resolution of metabolic clinical picture with basal $\mathrm{CH}$ normalization ( $\mathrm{CH}<2.5 \mathrm{ng} / \mathrm{ml}$ ), therefore fulfilling the cure criteria. Endonasal transsphenoidal endoscopic surgery may be the primary treatment for acromegaly, making transcranial approach in rare cases. Transsphenoidal cure rates are $75-95 \%$ and are related to tumor size, appearance and expansion, obtained by preoperative MRI.

\section{ANALYSIS OF THE PREVALENCE OF DIFFERENT ETIOLOGIES AMONG PRIMARY HEADACHES IN A SPECIALIZED NEUROLOGY OUTPATIENT CLINIC}

Isadora Alencar da Silva Andrade, Marcos Vinícius Bertoldo Comes $^{1}$, José da Cruz Moura Campelo', Guilherme Antonio Silva Ribeiro', Barhbara Brenda Dias Garcez' ${ }^{1}$ and Kelson James Silva de Almeida'

'Facid - Differential Integral College.

INTRODUCTION: Headaches (HD) are pains located in the cephalic segment They can be classified as primary: migraine, tension, cluster and others not associated with structural lesion, such as hypinic HD and those triggered by orgasm and physical activity. Secondary HD occurs when there is another pain-causing disease. HD are a frequent cause of work disability and one of the most common diseases in neurology outpatient clinics. Migraine is the primary HD most identified in health services because of its disabling potential and is more common in women. These may also be accompanied by gastrointestinal symptoms, transient neurological manifestations (auras) and associated phenomena (photo and phonophobia). OBJECTIVES: Quantify and qualify HD patients treated at a private health service in Teresina, Piauí. METHODS: This is a cross-sectional, observational study with quantitative approach and HD classification, conducted in a private hospital in Teresina. The study excluded the medical records of patients who had a diagnosis of secondary headache, altered tomography or magnetic resonance imaging of the skull, erythrocyte sedimentation rate and C-reactive protein. Data collection was performed by questionnaire applied during consultations and systematized later. RESULTS: Regarding the classification of the type of HD, of the total of 312 cases, the majority corresponded to migraine $(85 \%)$ and tension headache $(8.6 \%)$. The remaining cases presented trigemoneautonomic (1.3\%), cervicogenic $(1.3 \%)$, hypoxic $(0.6 \%)$, orgasmic $(0.9 \%)$ HD by physical activity (only 1 case)., or other causes $(2 \%)$. In the distribution of HD cases by gender, there was a predominance in females, being $83.3 \%$ of the total. The disposition of cases for each type of HD was predominant in females, occurring, migraine $(84.1 \%)$, tension $(88.8 \%)$, and cervicogenic (75\%). There were an equal number of cases for men and women in trigeminal autonomic type ( 2 cases each). The prevalence of males was higher only in orgasmic type (2 cases), and by physical activity (only 1 case). $19 \%$ (59 cases) presented HD-associated aura. CONCLUSION: The most frequent type of HD in this study was female-predominant migraine, in agreement with the literature already established.

\section{ANALYSIS OF THE CARE LINE OF PSYCHIATRIC PATIENTS IN PARNAÍBA} UNDER THE PERSPECTIVE MEDICINE STUDENTS OF UFPI-CMRV

Ariane Oliveira Dinato ${ }^{1}$, Lucas de Carvalho Techi', Isadora Maria de Almeida Morais ${ }^{1}$, Ravenna Araújo Santos ${ }^{1}$, Bruno Henrique Batista Valcácer ${ }^{1}$, Francisco Jander de Sousa Nogueira ${ }^{1}$ ${ }^{1}$ Federal University of Piauí

INTRODUCTION: Power over life, especially in the Mental Health bias, is given by social control. The practice of designating individuals as sick, socially or biologically, has been responsible for the spread of insane asylums around the world. Today, although obsolete, this form of biopolitics, fought by the antimanicomial Movement, is still practiced in Brazil, including Parnaíba, but temporarily - short hospitalizations, during outbreaks. OBJECTIVE: To know the view of the medical student in relation to the parnaiban setting of hospitalization in the psychiatric ward. METHODS: A qualitative ethnographic study was conducted from the reports of medical students after a visit to the psychiatric ward of the Santa Casa de Misericórdia Hospital in Parnaíba, Piauí. RESULTS: The students' first impression of the psychiatric ward of the Hospital Santa Casa de Misericórdia was striking, mainly referring to the structure of the place - surrounded by bars that mimic a prison, separating their patients into small cells"”. However, it should be agreed that such spatial structuring is necessary since, without it, patients end up fleeing or assaulting people in the vicinity. It is important to also highlight the imperative use of biopower in this wing, since patients are maintained "calmos" essentially by the medicamentosa, characterized as a treatment only symptomatic, it should be borne in mind that other therapeutic measures are not taken, propitiating the process of illness. Still, it is noticed that the creation of a link between professional and patient does not occur also due to the high rate of rotation of the wing employees. Finally, it is noteworthy that, despite the various problems observed by students, It is identified that the ward is one of the most effective exits against psychiatric emergencies in the city, since most health professionals and the general population are not prepared to act in a manner appropriate to a psychotic break. CONCLUSION: The psychiatric ward is the only place in Parnaíba that serves patients in outbreak. However, the physical structure available to receive them and the treatment employed do not guarantee the Iongitudinality of the care after the period of hospitalization. In view of this new outbreaks are not prevented, which promotes the process of illness, increases the costs of the health system and transforms the psychiatric ward into a place where health care is questionable following the logic of Humanization.

\section{ANALYSIS OF THE MAIN CAUSES OF DEATH OF HOSPITALIZED} PATIENTS IN BRAZIL IN THE AGE OF 1 TO 14 YEARS

Railda Pontes Saraiva de Moraes'; Saulo Edson Soares Timbó1; Sabrina Soares Timbó ${ }^{2}$; Laise Cajubá Almeida Britto ${ }^{1}$

${ }^{1}$ Federal University of Piauí. ${ }^{2}$ Unichristus

INTRODUCTION: Childhood mortality is a key indicator in assessing the health status of the population, so it was part of the Millennium Development coals. In addition, monitoring this indicator represents an opportunity for the development of preventive strategies to reduce the risk of death of children. It is important to highlight that the proportion of child deaths investigated in the country is still low, so it is important to pay more attention to the theme so that the investigation of deaths is effectively implemented, with a view to reducing mortality. OBJECTIVES: To analyze the 5 leading causes of death according to the ICD-10 chapter of individuals hospitalized in Brazil aged 1 to 14 years from 2013 to 2018. METHODS: Epidemiological, descriptive and retrospective study, whose data were obtained through consultation with the DATASUS Health Information System. SUS hospital morbidity data by place of hospitalization in Brazil were selected, specifically in the age group of 1-4 years, 5-9 years and 10-14 years, from 2013 to 2018. Among the twenty one causes of death listed, there was a restriction of the five main ones. RESULTS: In the age group of 1 to 4 years, there were 14906 deaths from all causes, the top 5 in decreasing order, 4120 from respiratory diseases (RDD), 3685 from infectious and parasitic diseases (PID), 1649 by neoplasia, 1154 from injuries, poisoning and some other causes resulting from external causes (EC) and 951 due to central nervous system diseases (DSN). In the age group from 5 to 9 years, there were 8123 , in decreasing order, 1777 by neoplasia, 1750 by DIP, 1466 by DAR, 804 by EC and 566 by DSN. In the age group of 10 to 14 years, there were 10059 deaths, 2076 from PID, 1843 from cancer, 1674 from DAR, 1413 from CE and 798 due to circulatory system diseases. CONCLUSION: There was a much higher death rate from all causes in the age group of 1 to 4 years, which was followed by the range of 10-14 years and then 5-9 years. In the three age groups analyzed, the following 4 causes were present as the main causes: DAR, DIP, neoplasia and EC, with the difference that at the age of 1 to 9 years, deaths from diseases of the nervous system are added, and 10 to 14 years, deaths from circulatory system diseases. Finally, the main causes of death in each age group analyzed, 1-4 years, 5-9 years and 10-14 years, were: DAR, neoplasia and PID.

\section{RARE CASE OF TUMOR OF PERIVASCULAR EPITELIOID CELLS (PECOMA) IN RETZIUS SPACE}

Marcos Vinícius Bertoldo Comes', Matheus Rodrigues Corrêa', Aline Reis Ferro Braga', Dimas de Sousa Correa Filho', Ione Maria Ribeiro Soares ${ }^{1}$ and Rafael de Deus Moura'. ' Federal University of Piauí

INTRODUCTION: Perivascular epithelioid cell tumor (PEComa) is a rare mesenchymal neoplasm, with just over 100 reports in the literature. They may be associated with tuberous sclerosis and may occur anywhere in the body; however, the most common forms of PEComa include angiomyolipoma, myomelanocytic clear cell tumor and lymphangioleiomyomatosis, characterized in immunohistochemistry by the expression of smooth and melanocytic muscle markers. OBJECTIVES: This case is a PEComa of soft tissue origin and located in the Retzius space, an atypical anatomical site. METHODS: An 18-year-old female patient reports 
that during routine pelvic ultrasound examinations in early 2014, she received a right annex hypoechogenic mass report measuring $7.8 \times 6.9 \mathrm{~cm}$. About four months later, the patient underwent computed tomography, which showed massive solid expansive formation with soft tissue alteration and small central cystic foci in the right adnexal region, measuring $9 \times 2 \times 8,2 \mathrm{~cm}$. Other exams without changes. Two months later, the patient underwent exploratory laparotomy, in which a retzius space tumor measuring $11.0 \times 9.5 \mathrm{~cm}$ was identified, with no changes in the ovary and uterus by surgical inventory. RESULTS: Histopathological examination revealed low-grade fusocellular mesenchymal neoplasia. Complementary immunohistochemical examination showed tumor positivity for smooth muscle actin and MART-1, consistent with PEComa. Postoperative abdominal and pelvic US examination came unchanged. CONCLUSION: PEComas are a challenging group of neoplasms due to their rarity. This case is of particular interest due to the atypical anatomical site. Knowledge about the malignancy potential of this neoplasia is still inaccurate, due to the scarce literature on the subject, which is mainly derived from few case reports and brief reviews. To date, the best treatment approach is surgical resection and clinical follow-up.

59.

REVIEW OF THE MORTALITY OF BRAZILIAN POPULATION FOR LEUKEMIA ON THE AGE GROUP OF O TO 14 YEARS

Railda Pontes Saraiva de Moraes; Saulo Edson Soares Timbó1; Sabrina Soares Timbó²; Laise Cajubá Almeida Britto ${ }^{1}$

${ }^{1}$ Federal University of Piauí. ${ }^{2}$ Unichristus.

INTRODUCTION: Although rare, cancer affects 1 in 600 children and adolescents, being the leading cause of death in people from 0 to 15 years. Early childhood cancer is often difficult to be diagnosed because it resembles common childhood illnesses. Leukemias are cancers of the hematopoietic system which involve the malignant transformation of lymphoid progenitor cells and, less commonly, myeloids. In addition they are the most common type of cancer in those under 15 years old, corresponding between $25 \%$ and $35 \%$ of all cancers. OBJECTIVES: The objective of this study was to analyze the mortality rate of the Brazilian population due to leukemia from o to 14 years old, from 2010 to 2017 , according to gender. METHODS: Epidemiological, descriptive and retrospective study, of which data were obtained by consulting the online Mortality Atlas of the National Cancer Institute (INCA). Information regarding the mortality rate of 100,000 individuals due to leukemia in the age groups 0-4, 5-9 and 10-14 years was selected, specifically the ICDs: C91-lymphoid leukemia, C92-myeloid, C93-monocytic, C94-other cell type specific leukemias and $C_{95}$ cell type leukemia without further specification. The numbers were divided by gender and refer to the period from 2010 to 2017. RESULTS: Regarding males, from 0-4 years old there were 898 deaths, from 5-9 years, 1063 and from 10-14 years, 1062, with relative rates of $1.48,1.63$ and 1.53 , respectively, reaching a total of 3023 male deaths. Regarding the female gender, from 0-4 years old, there were 824 deaths, from 5-9 years old, 674 and from 10-14 years old, 773 , with relative rates of $1.42,1.08$ and 1.16 , totaling 2271 deaths of women. Regarding deaths of the entire period, for both genders, 0-4 years, there were 1722 deaths, 5-9 years, 1737 and 1014 years, 1835 , with relative rates of $1.45,1,36$ and 1.34 , a total of 5294 deaths. CONCLUSION: Regarding gender, there was a higher prevalence of male deaths compared to female for all age groups, with a more significant difference in the age group of 5-14 years old and a close value in the range of $0-4$ years for both genders, which is corroborated by the total value of deaths in the period, which is 3023 deaths of men compared to 2271 deaths of women. Regarding the age group exclusively, a higher prevalence is observed with advancing age, with the highest number of deaths in the period referring to the age group of 10-14 years.

60.

ANALYSIS OF MORTALITY RATES FOR ALL TYPES OF LYMPHOMAS IN
BRAZIL IN THE 0-19 YEAR-OLD POPULATION OVER A PERIOD OF 20
YEARS

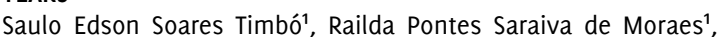

Sabrina Soares Timbón ${ }^{2}$, Laíse Cajubá Almeida Britto ${ }^{1}$

${ }^{1}$ Federal University of Piauí. ${ }^{2}$ Christus University-UNICHRISTUS.

INTRODUCTION: Lymphomas are the third most frequent type of cancer in children and adolescents, after leukemias and brain tumors, and are divided between non-Hodgkin's lymphoma and Hodgkin's lymphoma. They have a good prognosis, with an overall survival rate of up to $90 \%$, depending on the histological subtype and the stage. Its incidence increases with age, with $3 \%$ of cancers in children under 5 years and $24 \%$ of cases between 15 and 19 years. Pediatric cancer ranks second in causes of death in this age group, losing to external causes. OBJECTIVE: This study aims to analyze mortality rates for all types of lymphomas in the Brazilian population from o to 19 years old, from 1997 to 2017, based on the Brazilian population from 2010. METHODS: Epidemiological, descriptive and retrospective study, whose data were obtained by consulting the Atlas of On-line Mortality of the National Cancer Institute (INCA). The following age groups were selected: 0 to 4 years old, 5 to 9 years old, 10 to 14 years old, 15 to 19 years old, with mortality data per 100,000 men and women. ICDs C-81 (Hodgkin's disease) C-82 (Non-Hodgkin's lymphoma, follicular), C-83 (Non-Hodgkin's Diffuse Lymphoma), C-84 (Cutaneous and Peripheral T-cell lymphoma) and C-85 (Non-Hodgkin's lymphoma of other types, SOE) were used. It should also be noted that the evaluated period was from 1997 to 2017. RESULTS: In relation to the masculine sex, in the age group of o to 4 years, there were 496 deaths for 100.000 men and women; from 5 to 9 years, 692 deaths; from 10 to 14 years, 786 deaths, and from 15 to 19 years there were 1287 deaths for 100.000 men and women, making 3261 deaths from o to 19 years, of a total of 46.481 deaths of masculine sex. In relation to the feminine sex, it was obtained, in the range of 0 to 4 years, 241 deaths for 100.000 men and women; of 5 to 9 years, 280 deaths; of 10 to 14 years, 347 deaths, and of 15 to 19 it was obtained 676 deaths for 100.000 men and women, making 1544 deaths from o to 19 years, of a total of 36.641 deaths. CONCLUSION: In gender evaluation, there was a clear predominance of the highest mortality rate of all types of lymphomas in males in relation to females in all age groups, with the greatest discrepancy between the values in the 15-19 age group. This finding corroborates the epidemiology that points to a higher prevalence in males and the increase in the incidence of the disease with age, correlating with the growth of deaths and the increase in age group.

61. TEMPORAL TREND AND MAIN CAUSES OF CHILD MORTALITY IN SOUTHERN AND NORTHEASTERN BRAZIL: AN ANALYSIS FROM 2006 TO 2017

Maria Eduarda Lêmes Mora', Shana Ginar da Silva²

${ }^{1}$ State University of Fronteira Sul. ${ }^{2}$ State University of Pelotas.

INTRODUCTION: In the last 30 years, Brazil has undergone demographic, socioeconomic and infrastructural changes. In terms of health care, the country has evolved into a unified and expanded system for primary care, hence the infant mortality rates. However, there are still a number of obstacles to achieving the optimal values for the indicator in the country. In this sense, it is relevant to monitor and compare different national areas to determine public policies and target these regions and groups most at risk. OBJECTIVES: To analyze a temporal trend of infant mortality in two Brazilian states, Rio Grande do Sul and Piauí, and to identify the main causes from 2006 to 2017. METHODS: This is a statistical analysis of data from related information in the Mortality Information System (SIM) and Live Birth Information System (SINASC). Infant mortality rates and the leading causes of death were applied according to the categories of the 10th revision of the International Classification of Diseases (ICD-10). Data analysis was performed using descriptive statistics using absolute (n) and used (\%) frequencies. RESULTS: In 2006, the highest mortality rate (13.1 deaths per 1000 live births) in Rio Grande do Sul was observed in 2006. These taxis declined until 2011 and were established in 2015 to 2017, with a lower period index (10.07 deaths per 1000 live births). In Piauí, infant mortality indicators are recorded (19.8 per 1,000 live births) in 2007, with a decrease from 2008, reaching the lowest rates in 2015 (14, 82 deaths per thousand live births). It does not refer to the causes of death, which are the main causes of perinatal infections - leading cause, followed by congenital malformations, chromosomal deformities and anomalies, and respiratory diseases. CONCLUSION: Analysis of infant mortality rates in both Brazilian states declined for most of the period, showing an increase in 2016 in Piauí. However, this temporal trend demonstrates that the challenges remain especially to reach an acceptable number (10 deaths per 1,000 live births), advocated by the World Health Organization, overloaded in the perinatal component, or showing the importance of the factors associated with prenatal care, natal, birth and birth in various scenarios of the Brazilian territory. 
62.

\section{CHILD-ONSET SYSTEMIC LUPUS ERYTHEMATOSUS ASSOCIATED WITH OPTIC NEURITIS AND PRIOR HISTORY OF CHIKUNGUNYA VIRUS} INFECTION

Matheus Rodrigues Correa', Marcos Vinícius Bertoldo Comes ${ }^{1}$, Simone Soares Lima', Catarina Fernandes Pires', Roberta Oriana Assunção Sousa da Ponte Lopes².

${ }^{1}$ Federal University of Piauí. ${ }^{2}$ Lucidio Portella Children's Hospital.

INTRODUCTION: About $20 \%$ of patients with systemic lupus erythematosus (SLE) manifest a disease before age 18, mostly in adolescence. Multiple systems are accompanied by concurrently and evolutionarily. Juvenile onset, optic neuritis, and sensorineural hearing defects are presented, with severe impairment and risk of definitive sequelae. CASE REPORT: Adolescent, female, 13 years old, started 16 days before hospitalization, fever, hip pain and arthritis of the hands, knees, and feet. Within 24 hours, hyperemic lesions on the upper limbs appeared that were purple and then crusted. On the 10th day, he noticed persistent hearing loss for 3 days and bilateral progressive vision loss until amaurosis. On admission, adynamic, acyanotic, anicteric, eupneic, thin, lightly stained, normal cardiopulmonary auscultation and abdomen. Hypotrophied extremities and progressive weight loss. Quadriparesis, grade III muscle strength in the 4 limbs, with decreased reflexes in the upper limbs and exalted in the lower limbs. Good sphincter control. Brudzinski and Kernig were positive. Mydriatic pupils nonreactive. Magnetic resonance imaging (MRI) of the skull showed bilateral optic nerve realities, indicating optic neuritis. CT and brain magnetic resonance angiography and normal cervical spine MRI. Positive nuclear anticore factor $(1 / 80)$, reactive logical anticoagulant and weakly positive IgM anticardiolipin. Positive chikungunya serology (1/160) and PCR for Zika virus negative. Methylprednisolone started ( $30 \mathrm{mg} / \mathrm{kg} /$ day 05 days) with an improvement of systemic symptoms but little effect on vision. He the received human immunoglobulin $(2 \mathrm{~g} / \mathrm{kg})$, and no sixth day reported seein vultures and then black and white. Keep daily oral prednisone and monthly combined pulse (methylprednisolone and immunoglobulin) with full recovery of muscle strength, good cognitive ability, and independence for useful activities with partial visual impairment. CONCLUSION: SLE is a serious, multisystem disease with an unpredictable presentation, rangin from arthralgia to rare neurological manifestations such as optic neuritis Therapeutic success and prevention of sequelae depend on early diagnosis and treatment. The association of SLE with endemic viral diseases may slow them down. SLE should be investigated in patients with systemic manifestations for early diagnosis and improvement in prognosis.

\section{PRIAPISM AS THE FIRST CLINIC MANIFESTATION IN A PACIENT WITH} CHRONIC MYELOID LEUKEMIA

Haidyne Serra Lobão Lira', Hélio Fortes Napoleão do Rêgo Neto', Juliana Bezerra da Silva Moreno', Letícia Marques Wenzel ${ }^{1}$ Renato Martins Santana' and Mônica Fortes Napoleão do Rêgo' 'Facid-Wyden.

INTRODUCTION: Chronic Myeloid Leukemia (CML) is a chronic clonal myeloproliferative disease characterized by leukocytosis with left granulocytic cells, splenomegaly and the presence of the Philadelphia (Ph) chromosome and / or BCR-ABL gene. Priapism is a prolonged (from 4 continuous hours) and painful penile erection not associated with sexual stimulation and is considered a medical emergency. Idiopathic priapism is the most common, affecting about $64 \%$, while about $20 \%$ is related to hematological disorders (most commonly in sickle cell anemia). It's incidence in adult men with CML is only $1-5 \%$. Therefore, this case is patient with CML associated with a clinical presentation of priapism something rare and uncommon to be highlighted. CASE REPORT: PHM, 2 years old, male. He was admitted to the "Hospital de Urgência de Teresina" (HUT) with priapism and was submitted to aspiration of the corpus cavernosum. Two days later, he was transferred to the "Hospital São Marcos", presenting a painful and rigid penile region and splenomegaly. Complete blood count revealed: Hematocrit: $24.5 \%$, Hemoglobin: $8.3 \mathrm{~g} / \mathrm{Dl}$ Red blood cells: $2.720 .000 \mathrm{~mm} 3$, Leukocytes: $316.720 \mathrm{~mm}$, Myelocytes: $7 \%$, Metamielocytes: $9 \%$, Rods: $15 \%$, Segmented: $54 \%$, Eosinophils: $4 \%$, Basophils: $1 \%$, Lymphocytes: $8 \%$, Monocytes: $2 \%$ and Platelets: 318,000 mm3. Myelogram: hypercellular bone marrow with granulocytic hyperplasia. The karyotype examination was performed for diagnostic confirmation, which showed the presence of $t(9 ; 22)$ ( $934 ;$ q11.2) - Philadelphia chromosome and positive BCR-ABL transcript. Ultrasonography: signs of low output priapism. Medication therapy was started with the use of Hydroxurea (2g / day) initially and Allopurinol. After confirmation of $\mathrm{t}(9 ; 22)$ Hydroxyurea was suspended and was started, Imatinib Mesylate 400mg/day. FINAL CONSIDERATIONS: Leukocytosis in CML causes venous blood stasis and leads to low flow type priapism, also known as ischemic priapism. This is a rare presentation in $\mathrm{CML}$, so a complete blood count should be done in your primary investigation. Therefore, priapism is a medical and urological emergency requiring immediate local therapy, symptomatic treatment, cytoreductive therapy, and early initiation of targeted therapy.

\section{EFFICIENCY OF VACINAL COVERAGE FOR BCG AND HEPATITIS B IN PARNAÍBA/PI - A COMPARATIVE STUDY}

Maria Julia Rabeche Cornelio Oliveira', Adrielly Cristhine Gonçalves Araujo', Gabriel Phelipe Dantas do Nascimento', Luana Mazza Malta' and Renata Paula Lima Beltrão'

'State University of Piauí.

INTRODUCTION: It is recommended by the Ministry of Health that all newborns who do not have any contraindication can be immunized against tuberculosis, through the BCG vaccine and hepatitis B in the first hours of life. Given this premise, this paper analyzes the panorama of immunization coverage of these immunizations in Parnaíba / PI. OBJECTIVES: To analyze the effectiveness of vaccination coverage for BCC and hepatitis $B$ by comparing quantitative coverage data and live births in the city of Parnaíba / PI from 2015 to 2017. METHODS: A retrospective descriptive epidemiological study using data from the Health Information System, DATASUS. BCG and Hepatitis B vaccination coverage data were selected by comparing the percentage coverage values and the estimate of live births from 2015 to 2017 in Parnaíba / PI. RESULTS: According to the data provided by DATASUS, in 2015 there were a total of 2,434 live births in the city of Parnaíba / PI and a percentage of $181.97 \%$ for BCC vaccine coverage and $162.98 \%$ of Hepatitis $B$ for children up to 30 days of life. In 2016, 2,319 was the estimated number of live births, while vaccination coverage for BCC and Hepatitis B vaccines was, respectively, $203.37 \%$ and $132.84 \%$. In the following year, 2017 , the last year available on the DATASUS platform, the percentages of coverage were $213.09 \%$ for BCG and $194.86 \%$ for Hepatitis B, with 2,377 estimated live births in the year in question. CONCLUSION: From the comparative analysis between the number of live births and the percentages of coverage of BCC and Hepatitis B vaccines, it is noticeable that Parnaíba city exceeds its estimated population of newborns with regard to vaccine coverage. This is probably due to the fact that, according to the Brazilian Ministry of Health, the calculation of coverage should be performed from the doses that were applied by the city, which may have also been directed to the population of other cities, as the city of Parnaíba function as a pole. This form of calculation is even likely to hide possible cases of non-immunization. Therefore, it is necessary to create a strategy aimed at better clarifying the real scenario of vaccination coverage for such immunizations within the city of Parnaíba.

65.

CHARACTERIZATION OF THE EPIDEMIOLOGICAL PROFILE OF MATERNAL MORTALITY IN THE STATE OF PIAUÍ IN THE YEARS 2014 TO 2017

Danilo Andrade Lima', Jocerone Emerson Nogueira Oliveira', Igor dos Santos Cavalcante', João Pedro Sousa Mendes', Fellype Henrique Mendanha Pereira, Nayana Alves de Brito Melo Okasaki'.

1 Federal University of Piauí.

INTRODUCTION : Maternal mortality (MM) is defined as death during pregnancy or within 42 days of termination of pregnancy, regardless of duration or location of pregnancy due to any cause related or aggravated by pregnancy or for measures taken in connection with it. It is a health issue which is an important indication of the quality of care offered to women throughout the pregnancy-puerperal cycle (PCC). OBJECTIVES : To analyze the profile of cases of MM in the state of Piaui and its associated causes from 2014 to 2017. METHODOLOCY : Epidemiological, descriptive, quantitative and retrospective study of cases. based on data from the DATASUS platform. RESULTS : Were notified 147 maternal deaths. According to age group, $41.5 \%$ of cases occurred between 20 and 29 years, $34 \%$ between $30-39$ years and $18.4 \%$ between $10-19$ years. $34 \%$ of women were single. Regarding color / race, $69.4 \%$ of women were brown, $18.4 \%$ white and $6.1 \%$ Black Regarding education, the 4-7 years and 8-11 years of schooling equal values of $27.2 \% .87 \%$ of deaths occurred in a hospital environment, with those classified as direct obstetricians, due to complications during PGC, corresponding to $80.2 \%$, mainly eclampsia $(16.3 \%)$ and other maternal diseases $(17.7 \%)$, which followed in the postpartum period (60\%). The $20-29$ age group is the one with the lowest 
reproductive risk, a higher death rate warns of the need for strengthening assistance at the CGP. Poor education means less knowledge about Family Planning (FP) and reproductive health. Single women are more prone to death due to less social support, in which the partner is inserted. Color / race must be carefully evaluated as it allows identifying social issues or access to health. CONCLUSION : MM is associated with intersectoral and health care causes. Problems in the organization of the health system highlight the need for investments for training and qualification of professionals, greater engagement of the society and public agencies seeking greater commitment in the fight for the reduction of MM. Deaths in the extreme ranges of the reproductive phase could be minimized by improving health care, therefore, health education and FP strategies are essential for prevention of complications during PGC.

66.

\section{EMBRYONIC RABDOMYOSSARCOMA: A CASE REPORT}

Luiz Ferreira de Freitas Martins Neto' ${ }^{1}$, Hélio Fortes Napoleão do Rêgo Neto ${ }^{1}$, Camila Rosado Luz de Carvalho' ${ }^{1}$, Rodrigo Antônio Rosal Mota ${ }^{1}$, Tázia Maria de Souza Menezes ${ }^{1}$ and Mônica Fortes Napoleão do Rêgo' 'Facid-Wyden.

INTRODUCTION: Rhabdomyossarcoma (RMS) is a malignant neoplasm originating from primitive mesenchymal cells. It is the most common sof tissue sarcoma in children (50\%), and can occur anywhere on the body. The clinical expression of the disease is directly related to its location. Two major subtypes of RMS in childhood are identified: embryonic (60\%) and alveola $20 \%$ ), with distinct clinical characteristics and behavior. The embryonic occurs mainly in the head and neck, genitourinary tract and retroperitoneum. Thus, the objective of our work is to present the case of a 4-year-old boy with an Embryonic RMS, Botriid Variant of the Biliary Tract. CASE REPORT: MRS, male, 4 years old, with symptoms of abdominal pain fever and vomiting beginning in November / 2016. She was admitted to the Children's Hospital on $12 / 29 / 16$, with clinical worsening: Jaundice, choluria and persistent abdominal pain. Abdominal ultrasound and abdomen tomography were performed, which showed heterogeneous expansive lesion extending from the topography of the hepatic hilum to epigastrium mesogastrium. Cholangioresonance showed intra and extrahepatic bile duc dilation, thick material in the bile duct, cystic duct and bile ducts. Laboratory tests were: Hematocrit $-24 \%$, Hemoglobin $-8.1 \mathrm{~g} / \mathrm{dL}$, Platelets - 514,000, TCO - 187 U / L, TGP - 204 U / L, Alkaline Phosphatase - 1577 U / L, Gamma GT - $1370 \mathrm{U} / \mathrm{L}, \mathrm{DHL}-768 \mathrm{U} / \mathrm{L}$, Total Bilirubin - 8.7 mg / dL and Direct Bilirubin - $4.6 \mathrm{mg} / \mathrm{Dl}$. On 01/26/17, he underwent cholecystectomy (with biliary bypass), a Kehr drain was installed and a biopsy of the choledochal lesion was performed. Immunohistochemistry of Embryonic RMS-compatible biopsy material, Botrioid variant. Chemotherapy treatment was started and after completion there was complete regression of jaundice and $70 \%$ reduction in abdominal mass. Although undergoing chemotherapy and surgery with significant reduction of the tumor and regression of symptoms, the clinical picture worsened with tumor recurrence and liver failure, causing the child to progress to death. FINAL CONSIDERATIONS: The patient in question has a bile duct tumor and presents symptoms like jaundice, abdominal pain, and fever. Thus, in addition to cholecystitis, hepatitis A and Dubin-Johnson Syndrome, diseases that may also occur in the presence of these symptons, one should consider biliary RMS, an atypical but possible location for this kind of tumor.

67.

\section{A COMPARATIVE BETWEEN THE ESTIMATE OF PROSTATE CANCER AND} FEMALE BREAST CANCER IN THE LAST THREE BIENIANS IN BRAZIL

Danilo Andrade Lima', Jocerone Emerson Nogueira Oliveira', Igor dos Santos Cavalcante ${ }^{1}$, João Pedro Sousa Mendes ${ }^{1}$, Renata Paula Lima Beltrão'

${ }^{1}$ Federal University of Piauí.

INTRODUCTION: Cancer (CA) occurs when abnormal cells divide uncontrollably and destroy tissues. The prostate cancer (PC) and breast cancer $(B C)$ are the most prevalent types in men $(M)$ and women (W) respectively, excluding non-melanoma, so it is a public health problem. In Brazil, there are many campaigns to make people aware of the importance of early diagnosis (ED). However, many $M$ have resistance to going to the doctor and the touch exam is still a taboo. At the same time, women are more concerned and seek the health system more often. OBJECTIVES: To analyze the evolution and behavior of cases of $P C$ and $B C$ compared to the total cases of cancers in Brazil during the period from 2014 to 2019. METHODOLOGY: Cross-sectional study with quantitative approach. Data were collected in the system of the National Cancer Institute losé Alencar Comes da Silva (INCA). Estimates refer to the 3 bienniums from 2014 to 2019 and were statistically and graphically analyzed using an Exce spreadsheet. RESULTS: For each year of the biennium (BI) 2014/2015, the PC presented an estimated $68,800(22.8 \%)$ of new cases (NC), which corresponds to a risk of $70.42 / 100$ thousand $M$, whereas the female $B C$ was estimated at $55,120(20.8 \%) \mathrm{NC}$, a risk of $56.09 / 100$ thousand W. For the $2016 / 2017 \mathrm{BI}$ the PC was estimated at $61,200(28.6 \%) \mathrm{NC}$, a risk of $61.82 / 100$ thousand $\mathrm{M}, \mathrm{BC} 57.960(28.1 \%) \mathrm{NC}$, a risk of $56.20 / 100$ thousand $\mathrm{W}$. In the last $\mathrm{BI} 2018 / 2019$, the estimate was $68.220(31.7 \%)$ PC NC, a risk of $66.12 / 100$ thousand $M$, as for BC, 59,700 (29.5\%) NC is expected, a risk of 56.33/100 thousand W. CONCLUSION: In the period analyzed, PC is the most prevalent cancer among the $\mathrm{M}$ and the $\mathrm{BC}$ between the $\mathrm{W}$. The $\mathrm{PC}$ presents variation in the estimates, with reduction in the second $\mathrm{BI}$ and subsequent increase in the next BI. Considering that the number of $\mathrm{M}$ is lower than that of $\mathrm{W}$, $48.3 \%$ of the total population, it can be inferred that the prevalence of CA in $M$ is high and may be due to the resistance of the vast majority of them to seek health care preventive. In relation to the $M C$, there is a gradual increase in estimates. This fact may be closely related to the increase in pathology-oriented public policies, a fact that optimized standard deviation and increased data. Thus, popular health education is an effective way to achieve early detection of the disease, a fact that will influence the possible cure.

68

ECLAMPSIA IN THE NORTHEAST COMPARED TO THE OTHER BRAZILIAN REGIONS: AN EPIDEMIOLOGICAL CROSS-SECTIONAL PICTURE OF THE LAST DECADE

Cláudia Lima Mascarenhas Diniz', Alysson Leunam Meneses Vasconcelos' ${ }^{1}$, Adelmo Isaac Medeiros Avelino', Mariela Souza de Medeiros ${ }^{1}$, Lucas Marques Santiago ${ }^{1}$ and Ivan Rodrigues Silva'. 'State University of Piauí.

INTRODUCTION: Eclampsia is the maximum degree of severity of pregnancyspecific hypertensive disease. This disease presents a spectrum of great clinical and pathological variability, starting with the pre-eclampsia stage and ending with the primary episode of seizure during pregnancy of women who do not have neurological diseases, which characterizes eclampsia. Preeclampsia and eclampsia are one of the main causes of maternal morbidity and mortality in the world. Even though there has been a significant reduction in these episodes in developed countries, rates remain high in developing countries, such as Brazil. OBJECTIVE: To conduct a cross-sectional study comparing the occurrence of deaths from eclampsia in the Northeast region (NE) with the other regions of Brazil in the period 2007-2017. METHODOLOGY: Retrospective and quantitative research in DATASUS to analyze data from the Northeast region and the other regions of Brazil on the number of deaths due to eclampsia in the period 2007-2017. RESULTS: In 2017, 155 maternal deaths due to eclampsia occurred in Brazil. Of these 56 were in the NE region, which corresponds to more than $35 \%$ of deaths due to eclampsia in the country. This result puts the NE region ahead of the other Brazilian regions when comparing the number of deaths from eclampsia in 2017 and in the last ten years, in which the NE continues to lead the ranking. In 2016, the NE registered 59 deaths, followed by the Southeast (SE) with 41 deaths. In 2015, 74 deaths occurred in the NE, followed by the SE with 40 deaths. In 2014, 57 deaths in the NE, followed by 36 in the SE. In 2013, the NE presented more than 70 deaths. In 2012 , the NE had the highest rates. In 2011, the NE presented approximately $50 \%$ of the deaths. In 2010, the NE suffered 60 deaths, followed by the SE with 51. In 2009, 2008 and 2007, the NE presented more than 80 deaths in each year, which is equivalent to approximately $50 \%$ of the deaths. The numbers of deaths from eclampsia in the Northern region were just behind the SE region. The South and Midwest regions, on the other hand, had the lowest rates in the period. CONCLUSION: The Northeast stands out in the number of deaths due to eclampsia in Brazil, ranking first in the analyzed period. However, it is known that there are data that may be underreported and the rates are susceptible to change. Thus, special attention is needed to these pregnancy syndromes in this region, since they generate severe complications and maternal deaths. 
69. EARLY KWASHIORKOR SECONDARY TO SUCTION DEFICIT IN INFANT Alexandre Gabriel Silva Rego ${ }^{1}$, Lívia Rodrigues Santos', Simone Soares Lima', Ana Karoline Batista Burlamaqui Melo', Catarina Fernandes Pires', Marcia Maria Saraiva Fernandes Chaves' ${ }^{1}$ Federal University of Piauí.

INTRODUCTION: Protein energy malnutrition (PEM) is the second leading cause of death in children under five in developing countries. Kwashiorkor, a recognized syndrome of PEM, predominates in children older than two years and is associated with protein dietary deficiency. We report a case of Kwashiorkor in a young infant with a significant sucking deficit. CASE REPORT: Infant, 7 months old, born preterm (32 weeks), in good condition, weight (W) 2050 g, length (L) $41 \mathrm{~cm}$ and head circumference (HC) $31 \mathrm{~cm}$, Apgar $8 / 9$, high at 24 hours. Exclusive breastfeeding for 2 months, interrupted due to weak sucking and replaced by first semester infant formula ( $150 \mathrm{ml}$ every three hours), accepting 50ml at a time. At 4 months, the patient developed disseminated skin dermatitis with hyperemia, followed by blistering and sparse crusting of the skin, along with scaling lesions and generalized edema. On admission, teary, anasarc, slightly hypocolored, depigmented and brittle hair and presence of skin lesions with predominance in the lower limbs. W $4740 \mathrm{~g}, \mathrm{~L} 55 \mathrm{~cm}, \mathrm{HC} 40 \mathrm{~cm}$ (very low $\mathrm{W}$ and $\mathrm{L}$ and low $\mathrm{HC}$ for age). Normal cardiopulmonary auscultation. She had axial hypotonia, no cervical and trunk control, and no active search for objects. Presence of foodseeking reflex, but no digital sucking reflex, bite, or lip seal. Tests showed anemia (hemoglobin $9.3 \mathrm{~g} / \mathrm{dL}$ ), hypoalbuminemia $(2.3 \mathrm{~g} / \mathrm{dL}$ ), fecal fat loss (30\%) and elevated transaminases (AST $169 \mathrm{U} / \mathrm{L}$; ALT $66 \mathrm{U} / \mathrm{L}$ ). Negative investigation for cystic fibrosis, inborn error of metabolism, food allergy, hypothyroidism, adrenal hyperplasia, and intestinal parasitosis. Normal echocardiogram and skull tomography. Ultrasonography showed mild homogeneous hepatosplenomegaly. Started elementary diet with progression to If by nasogastric tube, iron supplementation, vitamin $D, A$, folic acid, speech therapy and physiotherapy. There was weight-height gain and complete acceptance of the age-appropriate oral diet, along with resolution of skin lesions and neurological delay. FINAL CONSIDERATIONS: Although the prevalence of nutritional deficit is decreasing, some population groups, such as children under 5 years old and less developed regions, are still affected by PEM, requiring a high degree of suspicion and an intensive, comprehensive and multidisciplinary approach to reduce morbidity and mortality. and prevent PEM-associated sequelae.

70.

\section{TOPIRAMATE-INDUCED ACUTE MYOPIA}

Marcela Maria Lopes Costa', Mariana Éllen Araújo Silva', Alexandra de Oliveira Lopes', Brenda Cavalcanti de Oliveira Melo', Thuane do Nascimento Bezerra', Raimundo Feitosa Neto ${ }^{2}$ ${ }^{1}$ State University of Maranhão. ${ }^{2}$ Federal University of Piauí.

INTRODUCTION: Migraine is a chronic neurological disorder characterized by headache episodes and other associated symptoms. Topiramate, approved for adult use in migraine prevention, is an anticonvulsant drug, widely used in neurology and psychiatry, but has adverse effects such as reversible loss of ability to recognize palates and odors and ophthalmic changes. In this context, although rare, acute angle closure glaucoma, Peri orbital edema, diplopia and acute myopia have been reported related to topiramate. Myopia usually occurs in association with angle closure glaucoma and the mechanism for this is due to anteriordisplacement of the lens-iris diaphragm, and anterior chamber shallowing, camerular sinus appositional induced by topiramate. However, such myopia is reversible upon discontinuation of the drug. CASE REPORT: Female patient, 29 years old, followed in Neurology outpatient clinic for severe migraines, with seizures that used to last about 3 days without improvement with analgesics. Given the need of prophylactic treatment with Topiramate, with a regimen starting at $25 \mathrm{mg}$ per day. When using the drug for about 5 weeks, she complained of reduced visual acuity with worsening with progressive use of Topiramate. On ophthalmological consultation, the patient presented with preservation of intraocular pressure in acceptable standards, but reduced visual acuity by 1 degree in the right eye and 0.75 in the left eye. With the discontinuation of the drug, the patient reports improvement in the visual condition, with prophylactic treatment replaced by Melatoni. CONCLUSION: Acute myopia has been documented in the scientific world as a side effect induced by acetazolamide sulfate derivatives, sulfamethoxazole-trimethoprim, promethazine, spironolactone among others. Currently, there have been few cases in the world literature with acute topiramate-induced myopia, used for the prophylaxis of recurrent migration crises. This adverse effect is usually evident in the first month of treatment with medication, and if the condition is diagnosed early, it is reversible with discontinuation of the drug and vigorous hydration for a short period. Resolution of the condition after drug withdrawal usually occurs within three to seven days.

71. THE EPIDEMIOLOGICAL PROFILE OF NOTIFIED CASES OF SEXUAL VIOLENCE AGAINST WOMEN IN PARNAÍBA CITY - PI

Cabriel Phelipe Dantas Do Nascimento', Camila Pereira Miranda Costa', Igor Dos Santos Cavalcante', Jardani Dias Vieira Da Cunha', Jocerone Emerson Nogueira Oliveira', Nayana Alves De Brito Melo Okasaki'.

' Federal University of Piauí - Campus Ministro Reis Velloso.

INTRODUCTION: Sexual violence is defined as any sexual act in which an individual is obliged to submit contrary to it's own will through physical force, coercion, seduction, threat or psychological influence, in addition to the fact that the aggressor can force the victim to perform some of these acts with others. Such aggression damages the physical, emotional, sexual, mental, social and reproductive well-being and may last the victim's entire life. Through the evaluation of violence indicators, intervention policies and prevention strategies can be planned and implemented, improving victims' reception, as well as the proper filling of information systems files, which are extremely important for public health. OBJECTIVES: Describe the epidemiological profile of notified cases of sexual violence against women in Parnaíba-PI, from 2009 to 2016, according to age group, race, relationship of the victim with the aggressor, education and place of aggression. METHODS: Epidemiological, quantitative research, whose data were taken from the "Sistema de Informação de Agravos de Notificação (SINAN)". Such data were grouped in Microsoft Excel spreadsheets and displayed in graphs and tables. RESULTS: It was found that of the 224 cases reported in the period, $67 \%$ occurred at the victim's residence, followed by $11 \%$ on public roads. Regarding the age group, the interval from 10 to 14 years ( $45 \%$ ) prevailed, followed by $22 \%$ from 5 to 9 years. Regarding the victim's relationship with the perpetrator, $35 \%$ was a friend or acquaintance of the victim, while $11 \%$ was unknown. Analyzing schooling, the prevalence was of victims who attended the 6th to gth grade $(29 \%)$. Regarding race, $64 \%$ declared themselves brown-skinned. Another relevant finding was that of the total reported cases, $63.8 \%$ were rape. CONCLUSION: It is noteworthy that, in most cases, the aggressor has ties with the victim, in addition to the aggression occur within the home. The prevalence of violence against brown-skinned women is probably related to the higher number of women of this race in the city. As for age, the fact that children are the hardest hit demands the approach sexual earlier. In addition, more than half of the reported cases were rape, wich is one of the leading causes of psychiatric illness in women. It was also detected the large number of information ignored in the SINAN files, highlighting the importance of training and awareness of health professionals in the proper completion of the system.

\section{SIGMOID VOLVULUS IN PREGNANCY: A CASE REPORT}

Gabriel Phelipe Dantas Do Nascimento', Isabella Pires Gomes Mendes', Camila Pereira Miranda Costa', Thainá Pinto Dos Santos ${ }^{2}$

1 Federal University of Piauí - Campus Ministro Reis Velloso. ${ }^{2}$ External Community

INTRODUCTION: The volvulus refers to the twisting of a part of the alimentary tract, being the sigmoid colon the most common site of occurrence. It arises when the mesentery is elongated and narrow or lacking fixation of the colon to the retroperitoneum. Although rare in pregnancy, the pregnancy may predispose such torsion as the pregnant uterus displaces the colon, explaining the frequency of presentation in the third trimester. Such pathology is associated with complications and high maternal and fetal mortality due to late diagnosis, as physiological changes in pregnancy may obscure the clinical presentation. Therefore, given the relevance of the theme to foster clinical reasoning, this case of sigmoid volvulus is reported in a 35-week pregnant woman. CASE REPORT: Female patient, 20 years old, farmer, from Araióses - MA. G2P1A0, 35 weeks of pregnancy and history of cesarean section 5 years ago. She complained of abdominal pain, associated with constipation8 days ago, and epigastric pain. On physical examination, normal fetal heartbeat, absence of uterine contractions, thick and impervious uterine lap, and little painful abdomen on palpation. At the abdominal ultrasound, intense meteorism and maternal constipation was evidenced. The patient was hospitalized and treated with laxatives and rectally glycerinated solution. Unresponsive to medication, the patient was admitted to the intensive care unit with severe abdominal pain, vomiting, fatigue, asthenia, anorexia, absence of flatus elimination and diffuse deep 
abdominal pain. She was confused, hypocolored and jaundiced. Laboratory tests showed leukocytosis and left shift, as well as severe hypokalemia. We opted for a laparotomy and therapeutic cesarean section. Operative findings revealed a volvulus in the sigmoid colon which was reduced manually. The newborn was taken alive, apgar 9/10, crying loudly, without apparent malformations, normopneic and weight of 1,825g. The patient evolved without complications and was discharged on the 4th postoperative day. FINAL CONSIDERATIONS: The reported prognosis of sigmoid volvulus is related to its stage. The maternal mortality associated with the viable intestine is only $5 \%$, however it increases to over $50 \%$ if intestinal perforation is present, which underscores the importance of early diagnosis and intervention. For this, it is necessary the physician's investigation for the pathology in question when this symptoms are presented by the pregnant woman, which becomes more common through the disclosure of cases like this.

THE INCIDENCE OF LEPROSY IN THE NORTHEAST UNDER A COMPARATIVE ASPECT BETWEEN THE REGIONS OF BRAZIL FROM 2014 TO 2017

João Pedro Sousa Mendes', Clara Cardoso Maia de Grammont², Jocerone Emerson Nogueira Oliveira', Igor dos Santos Cavalcante', Danilo Andrade Lima', Renata Paula Lima Beltrão'. ${ }^{1}$ Federal University of Piauí. ${ }^{2}$ Federal University of Maranhão.

INTRODUCTION: Leprosy is an infectious disease that mainly affects the skin and peripheral nerves. The disease has always had a heavy burden of social judgment, since in the past the sick were kept inmates away from social life. However, today the disease has treatment and cure. Brazil is the 2nd country with the largest number of new cases (NC), thus a national combat policy was created based mainly on early case detection. Currently, the Northeast, at the same time with high leprosy rates, has low rates of socioeconomic development and has the 2nd largest national population (27.69\%). OBJECTIVES: To compare the incidence rate (IR) of leprosy in the Northeast region compared to other Brazilian regions between 2014 and 2017. METHODOLOGY: Epidemiological and cross-sectional analysis of quantitative approach. The information was collected in the DATASUS system in the data section of the Information System and Notification Disorders (SINAN). The results from 2014 to 2017 were statistically and graphically analyzed using an Excel spreadsheet. RESULTS: In 2014 there were 31059 NC, of these, $1035(3.34 \%)$ belonged to the South (S), $4510(14.5 \%)$ to the Southeast (SE), $5878(18.9 \%)$ to the Central West (CW), $6113(19.68 \%)$ to the North $(\mathrm{N})$, and $13523(43.5 \%)$ to the Northeast (NE). In 2015, there were $28,758 \mathrm{NC}$, of which: $12,848(44.6 \%)$ in NE, 5667 (19.7\%) in CW, 5181 (18\%) in $\mathrm{N}, 4041(14.05 \%)$ in SE and $1021(3.55 \%)$ in S. In 2016, there was a regression to $25,214 \mathrm{NC}$, which $10984(43.5 \%)$ were in NE, $5092(20.19 \%)$ in $\mathrm{N}, 4701(18.65 \%)$ in CW, $3601(14.2 \%)$ in SE and S with $836(3.3 \%) \mathrm{NC}$. In 2017 , there were $26,689 \mathrm{NC}$, of these, $11,710(43.8 \%)$ in the NE, 5,337 $(20 \%)$ in the CW, $5111(19.15 \%)$ in the $\mathrm{N}, 3760(14.09 \%)$ in the SE, and $711(2.88 \%)$ in S. CONCLUSION: The reduction in the number of NC shows efficacy in disease control, but it is noticeable the regional discrepancies, as the NE presented $44 \%$ of the total NC in the period, while in the SE there were only $14.2 \%$. Analyzing the population proportion, the problem in the NE worsens, as the SE concentrates the largest population in the country, so the TP in the NE is much higher, which shows the influence of socioeconomic factors on disease transmission. At the same time it is noticeable an achievement of the Ministry of Health (MH) in early detection of the disease. However, a mapping of these problems by the MH is still necessary in order to improve the Social Determinants of Health in the NE and decrease its IR.

\section{4. \\ EPIDEMIOLOGICAL PROFILE OF CASES OF EXOGENOUS POISONING IN} THE PIAUÍ COASTAL PLAIN IN THE YEARS 2013 TO 2017

João Pedro Sousa Mendes ${ }^{1}$, Igor dos Santos Cavalcante', Danilo Andrade Lima', Jocerone Emerson Nogueira Oliveira', Vivianne Ferreira Bezerra², Renata Paula Lima Beltrão'.

${ }^{1}$ Federal University of Piauí. ${ }^{2}$ University of Fortaleza.

INTRODUCTION: Exogenous intoxication is defined as a set of harmful effects represented by clinical or laboratory manifestations that reveal the organic imbalance produced by the interaction of one or more toxic agents with the organism in the environment, such as contaminated drugs, pesticides or water and food. It corresponds to a dose-dependent effect, variable with the individual predisposition of the patient to local or systemic occurrence, depending on the physicochemical properties of the agent, its mechanism of action and the route of exposure. Therefore, it is an important public health issue, as it has a wide range and easy occurrence within the population. OBJECTIVES: To analyze the profile of exogenous poisoning in the Piauí Coastal Plain (PL) between 2013 and 2017. METHODOLOGY: Epidemiological, cross-sectional and quantitative work. Data from the Reporting Disease Information System (SINAN) were used, considering as variables: gender, age group, type of toxic agent and circumstance in which notifications occurred in the period. RESULTS: A total of 545 cases of exogenous poisoning were found, with women representing $61.4 \%$ of these and men $38.5 \%$. The most affected age group was 15 to 39 years $(49.9 \%)$, followed by 1 to $14(27.5 \%)$ and 40 to $64(15.2 \%)$. Regarding the toxic agent, the most frequent were drugs $(55.7 \%)$, food and drink (14.3\%) and rat poison $(7.3 \%)$. The circumstances in which the majority of poisonings occurred were suicide attempts $(40.5 \%)$, accidents $(19 \%)$, therapeutic use $(6.4 \%)$ and self-medication $(4.2 \%)$. Still, it is noteworthy that suicide attempts by poisoning in PL represent $9.4 \%$ of the total cases in Piauí, which were 2346. CONCLUSION: It is noticed that the population most affected by poisoning were young and adults, with a predominance of females. The most frequent intoxication was the drug, so this agent draws attention, given the ease of purchase and consumption of drugs without prescription. Also, the high number of suicides in PL requires attention, being this the main circumstance of poisoning. Accidents as the second largest cause warn of the need for popular education in the handling of toxic agents. By profiling the coastal plain poisoning, it is possible to develop a better approach and more efficient strategies to reduce this problem. 